\title{
TRADICIÓN Y REVOLUCIÓN EN LA FORMACIÓN DEL ESTADO EN CHILE POST-INDEPENDIENTE: LAS ASAMBLEAS PROVINCIALES (1822-1830)
}

\author{
Cristóbal García-Huidobro Becerra \\ Universidad de Santiago de Chile \\ cristobal.garcia-huidobro@usach.cl
}

El propósito de este trabajo es estudiar el surgimiento y desarrollo de las asambleas provinciales en Chile, durante el periodo post-independentista, abarcando el foco de la investigación desde 1822 hasta 1830. Asimismo, otro objetivo de esta investigación es estudiar el impacto que tuvieron dichas asambleas en la conformación del Estado chileno, especialmente si se considera que estas instituciones fueron una expresión mayor del gobierno municipal beredado del Antiguo Régimen, y que mantuvieron de alguna forma vivos los principios jurídicos y doctrinas politicas de dicho sistema, coexistiendo dificultosamente con las ideas de las revoluciones independentistas en Hispanoamérica.

PALABRAS CLAVE: Asambleas provinciales, Chile, Estado, Antiguo Régimen, gobierno municipal.

\section{TRADITION AND REVOLUTION IN THE FoRMATION OF THE STATE IN POST-INDEPENDENT Chile: the Provincial Assemblies (1822-1830)}

The object of this paper is to study the emergence and development of provincial assemblies in Chile during the post-independence period, encompassing from 1822 to 1830. Another objective of this research consists of studying the impact that these assemblies had on the conformation of the Chilean State, especially if it is considered that these institutions became a larger expression of the municipal government inherited from the Ancien Régime, somebow keeping alive the legal principles and political doctrines of this system in an uneasy coexistence with the ideas of the revolution in Spanish America.

KEYWORDS: Provincial Assemblies, Chile, State, Ancien Régime, municipal government.

[Recibido: 1/2/18; Aceptado: 3/7/18] 


\section{Introducción}

Este trabajo propone que el papel jugado por las asambleas provinciales, como también el de los cabildos durante el proceso de consolidación política vivido por Chile entre 1822 y 1830, fue fundamental como un contrapeso a las pretensiones de Santiago de erigirse como centro de la República, ya fuere influyendo en la distribución del poder político-administrativo o tomando parte en la construcción y aplicación de ciertos modelos formales de Estado, como fue el caso del sistema federal o del sistema unitario descentralizado consagrado en la Constitución Política de 1828. Así entonces, será objeto de este artículo estudiar el origen, conformación y organización de estos entes de administración, tomando en consideración su progresiva institucionalización político-constitucional.

Por otra parte, también se propone en esta investigación que los conflictos que dieron origen a las asambleas fueron indicadores de la transición paulatina que se verificó en el paso del Antiguo Régimen colonial al modelo revolucionario. De esta forma, las asambleas provinciales tendrán un carácter de órgano de transición desde el modelo colonial de representación corporativa, hacía un modelo alineado, al menos formalmente, con los parámetros ideológicos revolucionarios y republicanos. Esto traerá un cambio de paradigma en lo político, dado el tránsito desde un modelo en el que la soberanía residía y era ejercida por las instituciones corporativas de representación —-de acuerdo a las doctrinas de la monarquía pactista en la península-, entrando en colisión con las ideas nacidas de las Revoluciones Atlánticas, en que el Estado, ya fuera unitario o federal, centralizado o descentralizado, republicano e incluso monárquico, se convertirá en el detentor principal, sino único, del poder soberano consagrado por medio de un sistema constitucional. ${ }^{1}$

En el caso de Chile, dicho conflicto se evidenciará en la pugna surgida entre el gobierno central, los cabildos y eventualmente con las mismas asambleas provinciales al ser éstas la expresión máxima del poder conjunto e intereses de los «pueblos» reunidos, es decir, de los vecinos prominentes políticamente organizados y representados por sus respectivos concejos municipales, frente a una concepción ideológica que, en la teoría, se oponía a cerca de tres siglos de tradición de gobierno. ${ }^{2}$

1. Dym, Jordana, From Sovereign Villages to National States. City, State and Federation in Central America 1759-1839, Albuquerque, University of New Mexico Press, 2006, pp. 19-31; Chiaramonte, José Carlos, Nación y Estado en Iberoamérica. El lenguaje político en tiempo de las independencias, Buenos Aires, Sudamericana, 2004, pp. 64-65 y Verdo, Geneviève, «¿Soberanía del pueblo o de los pueblos? La doble cara de la soberanía durante la revolución de la independencia (1810-1820)», Andes, Universidad Nacional de Salta, n. ${ }^{\circ} 13$, Salta, 2002.

2. Quijada, Mónica, «Las dos tradiciones»: Soberanía popular e imaginarios compartidos en el mundo hispánico en la época de las grandes revoluciones atlánticas», en Rodríguez, Jaime (coord.), Revolución, independencia y las nuevas naciones de América, Madrid, MAPFRE, 2005, pp. 61-86, y de la misma autora «La potestas populi: una revisión del pensamiento político hispánico y la modernidad», en Bragoni, Beatriz y Sara Mata (eds.), Entre la Colonia y la República: insurgencias, rebeliones y cultura política en América del Sur, Buenos Aires, Prometeo, 2008, pp. 39-42. 


\section{Nacional contra local}

Desde los primeros momentos de la colonización, y paradójicamente reforzadas con las políticas borbónicas de fundación de asientos urbanos, ${ }^{3}$ las ciudades y sus respectivos cabildos fueron considerados espacios de organización y representación política, en que una comunidad formada por vecinos se estructuraba administrativamente por medio su concejo. ${ }^{4}$ Este modelo, denominado por los juristas españoles como «república», fue una realidad físico-política tangible, y solo en este espacio se legitimaba la autoridad en forma racional, por sobre la concepción de la imposición de la voluntad omnímoda del monarca. Así entonces, «(...) cuando los cabildos decaían en España, se consolidaban en América como las primeras instituciones de los nacientes municipios hispanoamericanos. Al fundar las nuevas ciudades, todos los conquistadores tuvieron en cuenta los cabildos municipales, como núcleos aglutinantes de la vida política y social».5

El asidero jurídico y filosófico de este concepto de «república» parece encontrar su sustento en las teorías medievales del origen popular del poder del rey y del pacto subyacente entre este último y su pueblo. Esto, por lo demás, estaba bien arraigado en la doctrina jurídica castellana, como es el caso de las Siete Partidas, de Alfonso X, que definen al «pueblo» como «un concejo de todos los residentes de la comunidad». ${ }^{6}$ De esta forma, la soberanía no estaba dada por la suma de soberanías individuales, sino que su concepción era corporativa. Por ende, no existía verdadero ejercicio soberano de representación sin concejo y sin ciudad, ${ }^{7}$ incluso llegando a entrar en algunas ocasiones en conflicto con la soberanía regia. ${ }^{8}$

3. Ejemplos bien estudiados los podemos encontrar en Dym, Jordana, «Our Pueblos, Fractions with No Central Unity: Municipal Sovereignty in Central America, 1808-1821», Hispanic American Historical Review, vol. 86, n. ${ }^{\circ}$ 3, Washington, 2006, pp. 431-466. Para el caso chileno véase Barbier, Jacques, «The Culmination of the Bourbon Reforms, 1787-1792», Hispanic American Historical Review, vol. 57, n. ${ }^{\circ}$ 1, Washington, 1977, pp. 51-68; Lorenzo, Santiago, «Concepto y funciones de las villas chilenas del siglo XVIII», Historia, n. ${ }^{\circ} 22$, Santiago, 1987, pp. 91-105 y Collier, Simon, Ideas and Politics of Chilean Independence, 1808-1833, Cambridge, Cambridge University Press, 1967, pp. 7-15. Un análisis más general, a nivel hispanoamericano lo podemos encontrar en Lockhart, James y Stuart Schwartz, Early Latin America. A bistory of colonial Spanish America and Brazil, Cambridge, Cambridge University Press, 1983.

4. Lorenzo, Santiago y Rodolfo Urbina, Origen de las ciudades chilenas, Santiago, Andrés Bello, 1983, pp. 19-21; Kinsbruner, Jay, The Colonial Spanish-American City: Urban Life in the Age of Atlantic Capitalism, Austin, University of Texas Press, 2005, pp. 1-8; Hoberman, Louisa y Susan Socolow (comp.), Ciudades y sociedad en Latinoamérica colonial, México D.F., Fondo de Cultura Económica, 1992, pp. 7-26.

5. Ocampo, Javier, «Independencia y Estado Nación», en Ocampo, José Fernando, Historia de las ideas politicas en Colombia, Bogotá, Taurus, 2008, p. 31.

6. Las Siete Partidas, Ley 1. ${ }^{a}$, título X, Partida 2. ${ }^{a}$. Sobre los alcances del concepto de soberanía véase Goldman, Noemí (ed.), Lenguaje y revolución: conceptos políticos clave en el Río de la Plata, 1780-1850, Buenos Aires, Prometeo, 2010, p. 15 y ss.

7. Alemparte, Julio, El cabildo en Chile colonial, Santiago, Editorial Andrés Bello, 1966, p. 32; Salazar, Gabriel, Construcción de Estado..., cit., pp. 46-57 y Del Valle, Laura Cristina, Los hijos del poder. De la élite capitular a la Revolución de mayo: Buenos Aires 1776-1810, Buenos Aires, Prometeo Libros, 2014, p. 13.

8. Meza, Néstor, La conciencia política chilena durante la monarquía, Santiago, Universitaria, 1958, pp. 166-167; Bravo Lira, Bernardino, Por la razón o la fuerza: el estado de derecho en la historia de Chile, Santiago, Ediciones Universidad Católica de Chile, 1996, pp. $63-66$ y p. 70. Esto podía ocurrir en cuatro casos, de 
Estas doctrinas tradicionales pasaron a América cuando fue necesario organizar el territorio conquistado y encontraron un espacio ideal para su enseñanza y expansión en las universidades indianas. Las obras de autores de la neoescolástica española como Luis de Molina, Francisco de Vitoria, Martín de Azpilcueta, Juan de Mariana, Domingo de Soto y Francisco Suárez, entre otros, fueron parte integral de los currículos de derecho y filosofía universitarios, por lo que sus ideas y doctrinas sobre el origen del poder soberano y la limitación ética y moral de su ejercicio, basadas en las premisas del Derecho $\mathrm{Na}$ tural, se convirtieron en parte de la cultura política y jurídica en las Indias. ${ }^{9}$ A mayor abundamiento, estos autores también reflexionaron sobre la participación del pueblo en la generación de dicho poder, aunque en forma limitada, pero siempre como detentor de un espacio inalienable de soberanía. ${ }^{10}$ Este principio estaría afincado en las tradiciones y costumbres políticas e históricas de gobierno municipal en la América Española, desde la fundación de los primeros cabildos y mantenida en el tiempo por los intereses de las élites locales, sin que Chile fuese una excepción. ${ }^{11}$

Con el paso del tiempo, el cabildo indiano se convirtió en un efectivo representante de los intereses locales dentro del sistema de gobierno imperial e incluso en un espacio de

acuerdo con la doctrina jurídica indiana, siendo estos: «obrepción»: producto de un vicio consistente en que el Rey había dictado la ley con desconocimiento de los hechos, «subrepción»: al existir un vicio consistente en que el Rey había dictado la ley fundado en hechos falsos; «escándalo conocido»: si la aplicación de la ley los produjere; y «daño irreparable»: si la aplicación de la ley lo produjere.

9. Véase Barrientos, Javier, La cultura jurídica en el Reino de Chile: bibliotecas de ministros de la Real Audiencia de Santiago (siglos XVII-XVIII), Santiago, Ediciones Universidad Diego Portales, 1992, pp. 82-84; Levene, Ricardo, El mundo de las ideas y la revolución hispanoamericana de 1810, Santiago, Editorial Jurídica de Chile, 1956, pp. 115-33; Hanisch, Walter, En torno a la filosofía en Chile: (1594-1810), Santiago, Universidad Católica de Chile, 1963, pp. 44 y ss.; Góngora, Mario, Estudios de historia de las ideas y de historia social, Valparaíso, Ediciones Universitarias de Valparaíso, 1980, pp. 71-125; Huneeus Pérez, Andrés, Historia de las polémicas de Indias en Chile durante el siglo XVI, 1536-1598, Santiago, Editorial Jurídica de Chile, 1960.

10. Font, Pablo, «El núcleo de la doctrina de Francisco Suárez sobre la resistencia y el tiranicidio», Pensamiento, vol. 69, n. ${ }^{\circ}$ 260, Madrid, 2013, pp. 502 y 505; Burlando, Giannina, «Virtud política y método histórico rupturista en Francisco Suárez», Veritas, n. ${ }^{\circ}$ 32, Casablanca, 2015, p. 69; Chiaramonte, José Carlos, Fundamentos políticos e intelectuales de las independencias. Notas para una nueva bistoria intelectual de Iberoamérica, Buenos Aires, Teseo, 2010, pp. 18 y 67; García-Gallo, Alfonso, «El derecho indiano y la independencia de América», Revista de Estudios Políticos, n. ${ }^{\circ}$ 60, vol. XL, Madrid, 1951, pp. 160-162; Dawyd, Darío, «Las independencias hispanoamericanas y la tesis de la influencia de las doctrinas populistas», Temas de Historia argentina y americana, ${ }^{\circ}{ }^{\circ} 16$, Buenos Aires, 2010, pp. 108-114; Bushnell, David, «La independencia de América del Sur española», en Bethell, Leslie, Historia de América Latina, tomo V, Barcelona, Crítica, 1991, p. 77.

11. Sus obras fueron parte de los currículos en las universidades chilenas, ya fueran la Universidad Pontifica de Santo Tomás en Santiago (1622) y la Universidad Pencopolitana en Concepción (1724). Posteriormente también fueron incluidos en los currículos de la Universidad de San Felipe (1747), manteniendo su actualidad en el pensamiento político y jurídico del país. Véase Salazar, Gabriel, Construcción de Estado en Cbile (18001837), Santiago, Sudamericana, 2006, p. 49; Góngora, Mario, «Aspectos de la Ilustración Católica en el pensamiento y la vida eclesiástica chilena (1770-1814)», Historia, n. ${ }^{\circ}$ 8, 1969, pp. 43-73. Complementan estos argumentos las obras de Mellafe, Rolando et al., Historia de la Universidad de Chile, Santiago, Editorial de la Universidad de Chile, 1992, pp. 21-25 y 32-34; Bravo Lira, Bernardino, La universidad en la historia de Chile, 1622-1992, Santiago, Pehuén, 1992. 
ejercicio político ciudadano, como lo indica Tamar Herzog. ${ }^{12}$ Era un espacio institucional que «ofrecía el marco de reunión, de poder, de encuentros y hasta de desencuentros para los integrantes de las familias más conspicuas del lugar». ${ }^{13}$

$\mathrm{Al}$ ser representante de los vecinos prominentes de una ciudad, si el cabildo percibía que las decisiones de un funcionario real eran perjudiciales para los intereses de la comunidad, dicho organismo utilizaría todo su poder para defender tales intereses, y pese a que los cabildos americanos carecían del derecho de enviar procuradores a las cortes del reino, de todas formas, se les permitía tener sus cabilderos cerca del asiento de poder en España con el fin de influenciar las políticas de la metrópoli. ${ }^{14}$

Como puede apreciarse, el concepto de que los cabildos eran unidades políticas locales erigidas como custodios de los derechos políticos de la comunidad tenía larga data, y pese al advenimiento de la revolución de la independencia, por lo menos en Chile dicha concepción pareciera no haber sufrido mayor variación, al menos en un primer momento. ${ }^{15}$ Las ciudades y pueblos de una provincia se atribuían una serie de derechos y prebendas consideradas inalienables, por lo que cualquier intento de conculcar dichas pretensiones podía devenir en una instancia de resistencia o incluso rebelión frente a lo que se consideraba como un acto propio de una tiranía. ${ }^{16} \mathrm{~A}$ mayor abundamiento, derivada de las doctrinas escolásticas y de las Partidas de Alfonso X, la noción de que el origen del poder regio se encontraba establecido en un acuerdo o pacto expreso o tácito entre el rey y el pueblo, se encontraba bien asentada, y queda aún más en relieve si tomamos en consideración que buena parte de las juntas formadas luego de la prisión de Fernando VII en 1808, acudieron a las Partidas para justificar su creación, basándose en el principio de retroversión de la soberanía a los pueblos. ${ }^{17}$ Esta fue la postura tomada por el cabildo de Santiago, cuyo procurador se basó en dicho texto para justificar la creación de la Junta de Gobierno, e incluso el mismo Bernardo O’Higgins usó los mismos argumentos en el manifiesto que publicó justificando la declaración de independencia de Chile. ${ }^{18}$

12. Herzog, Tamar, Defining nations. Immigrants and citizens in Early Modern Spain and Spanish America, New Haven, Yale University Press, 2003, pp. 43-45 y 52-61.

13. Del Valle, Laura Cristina, Los bijos del poder..., cit., p. 13.

14. Recopilación de leyes de los reinos de las Indias, Libro IV, título IX, ley V.

15. Eyzaguirre, Jaime, Ideario y ruta de la emancipación chilena, Santiago, Universitaria, 1986, p. 38; Alemparte, Julio, El cabildo..., cit., p. 261 y Amunátegui, Miguel Luis, Los precursores de la independencia de Chile, tomo I, Santiago, Imprenta de la República, 1870, p. 28.

16. Cavieres, Eduardo, Sobre la independencia en Chile. El fin del Antiguo Régimen y los orígenes de la representación moderna, Valparaíso, Ediciones Universitarias de Valparaíso, Pontificia Universidad Católica de Valparaíso, 2012, pp. 245-247 y 253.

17. Pérez, Joseph y Armando Alberola (eds.), España y América entre la Ilustración y el liberalismo, Alicante-Madrid, Casa de Velásquez, 1993; Del Alcázar, Joan, et al., Historia contemporánea de América, Valencia, Universidad de Valencia, 2007, p. 85; Luque Talaván, Miguel, Un universo de opiniones: la literatura jurídica indiana, Madrid, CSIC, 2003, p. 134.

18. José Miguel Infante, procurador del Cabildo de Santiago, justificó la creación de la Junta en la Ley 3.a , título XV, Partida 2. ${ }^{a}$. Véase «Acta del Cabildo de Santiago, 14/08/1810» en Actas del Cabildo de Santiago, vol. XIX, Santiago, Imprenta Cervantes, 1910, p. 35 y O'Higgins, Bernardo, Manifiesto que hace a las naciones 
Con todo, al examinar la evolución de la representación política en Chile, aparece de forma clara que el cambio experimentado en dichas materias implicó una transposición paulatina entre elementos tradicionales y modernos desde el punto de vista político e incluso jurídico, en vez de ser un quiebre abrupto producto de la imposición de los preceptos de la Revolución por sobre los del Antiguo Régimen. ${ }^{19}$ Con esto, se quiere reafirmar la idea de que no se niega la influencia sustancial de las ideas ilustradas y revolucionarias, que tuvieron un gran impacto en las independencias, así como en la gestación de los Estados hispanoamericanos. ${ }^{20}$ Ya fuera por virtud de los libros que llegaban al país o por quienes viajaban entre la América Española y Europa, estas ideas serán fundamentales para comprender en buena parte el sustrato doctrinal del proceso independentista chileno. ${ }^{21}$

Pero al mismo tiempo, es dable proponer que la prevalencia de ciertas doctrinas como la retroversión de la soberanía, e incluso la subsistencia del concepto de «pueblos» como depositarios originarios del poder soberano, indican que la adopción del ideario revolucionario no fue tan drástica como parte de la literatura histórica pareciese indicar, y será este el sustento jurídico y político al que apelarán en Chile los cabildos en las provincias de Concepción y Coquimbo, al enfrentarse ante las pretensiones de Santiago de controlar las instancias de gobierno y representación locales frente a un concepto de estado en vías de centralización, estructurado precariamente sobre principios todavía extraños a la cultura política chilena. ${ }^{22}$

el Director Supremo de Chile de los motivos que justifican su revolución y la declaración de su independencia, Santiago, Xara y Molinare, 1818, p. 7.

19. Guerra, François Xavier, Modernidad e independencias: ensayos sobre las revoluciones hispánicas, México D.F., Fondo de Cultura Económica, 1993. En términos generales este tema ha sido abordado por Rodríguez, Jaime, The Independence of Spanish America, Cambridge, Cambridge University Press, 2009. Finalmente, otra aproximación similar la podemos ver para Centroamérica en Dym, Jordana, From Sovereign Villages..., cit., capítulos I y II. También Alfredo Jocelyn-Holt y Bernardino Bravo Lira han hecho lo propio; el primero rescatando en cierta medida la tradición liberal, sintetiza los elementos de tradición y modernidad en el desarrollo intelectual y político de la sociedad chilena; y el segundo, al desarrollar y aplicar el concepto de «constitución histórica» que se entremezclaba con la «constitución escrita» de cuño revolucionario a partir de la independencia, aunque ambos no lo vinculan con el fenómeno de las tensiones entre capital y provincias en Chile. Véase Bravo Lira, Bernardino, Constitución y reconstitución: historia del Estado en Iberoamérica (siglos XVI al XXI), Santiago Abeledo Perrot, Legal Publishing, 2010 y Jocelyn-Holt, Alfredo, La independencia de Chile: Tradición modernización y mito, Santiago, DeBolsillo, 2009.

20. Hanisch, Walter, En torno a la filosofía..., cit., pp. 111-112; Villalobos, Sergio, Tradición y reforma en 1810, Santiago, Ediciones de la Universidad de Chile, 1961, p. 70.

21. Véase Gazmuri, Cristián «Libros e ideas políticas francesas en la gestación de la independencia de Chile», Caravelle. Cahiers du monde hispanique et luso-brésilien, n. ${ }^{\circ}$ 54, París, 1990, pp. 179-207; Pérez Godoy, Fernando, «La presencia de las ideas políticas de Samuel Pufendorf durante la independencia de Chile», Revista de Derecho y Humanidades, n. ${ }^{\circ}$ 17, Santiago, 2011, pp. 1-17; Kaplan, Lawrence, Entangling Alliances with None: American Foreign Policy in the Age of Jefferson, Kent, Kent University Press, 1987, p. 166; Levene, Ricardo, El mundo de las ideas..., cit., pp. 219-220; Amunátegui, Domingo, «Génesis de la independencia de Chile», Anales de la Universidad de Chile, n. ${ }^{\circ} 118$, Santiago, 1960, p. 49; Campos Harriet, Fernando, Veleros franceses en el Mar del Sur, Santiago, Zig-Zag, 1964, p. 134 y García-Huidobro Becerra, Cristóbal, «El reglamento constitucional provisorio de 1812: reflexiones para un bicentenario», Revista Chilena de Derecho, vol. 39, n. ${ }^{\circ} 1$, Santiago, 2012, pp. 241-242.

22. López, Elvira, El proceso de construcción estatal en Cbile. Hacienda pública y burocracia (1817-1860), 


\section{La revolución autonomista de $\mathbf{1 8 2 2 - 1 8 2 3}$ y el surgimiento las primeras asambleas provinciales}

Durante el transcurso del año 1818, el Director Supremo Bernardo O’Higgins, hizo presente la necesidad de dotar al país de una constitución que asegurase no solo la estabilidad institucional de un territorio que recientemente había proclamado su independencia, sino que también le diese mayor grado de legitimidad como gobernante. ${ }^{23}$ Sin embargo, temiendo que un código político impuesto desde la capital le granjease la resistencia de los pueblos, cuando buena parte del sur del país todavía se encontraba bajo el control de los remanentes del ejército del rey o de guerrillas formadas por criollos, españoles e indígenas que defendían la causa de la monarquía, O’Higgins prefirió obrar con prudencia y convocó a la población del territorio no ocupado del país, por medio de sus cabildos, para que suscribieran un proyecto constitucional de carácter provisional mientras se normalizaba la situación, ya que en sus palabras:

Un Congreso Nacional no puede componerse sino de los diputados de todos los pueblos, y por ahora sería un delirio mandar a aquellos pueblos que eligiesen sus diputados, cuando aún se halla la provincia de Penco, que tiene la mitad de la población de Chile, bajo el influjo de los enemigos. La nulidad sería el carácter más notable de aquel cuerpo constituyente, que se formase sobre un cimiento de agravios inferidos a la mitad de la Nación. La rivalidad de las provincias se seguiría por único resultado de las sesiones del Congreso. El desorden, en fin, y la guerra civil, tal vez, serían los frutos de una congregación extemporánea. (...)

Jamás se dirá de Chile que, al formar las bases de su Gobierno, rompió los justos límites de la equidad; que puso sus cimientos sobre la injusticia; ni que se procuró constituir sobre los agravios de una mitad de sus habitantes. ${ }^{24}$

No obstante, una vez que el Director Supremo creyó haber consolidado de mejor forma su posición al mando de los destinos de la República, su reconocimiento a los derechos de las provincias y la fuerza política de sus cabildos pareció desaparecer. En medio de una campaña modernizadora que incluyó la abolición de los títulos de nobleza, los escudos de armas y la prohibición de los juegos de azar, así como un intento fallido por abolir los mayorazgos, ${ }^{25}$ O’Higgins promovió la promulgación de una nueva constitución, esta

Santiago, DIBAM-CIDBA, 2014, pp. 29-34. El trabajo de López ha sido pionero en estudiar el desarrollo y evolución de la burocracia en Chile, poniendo de relieve la precariedad del estado central chileno. De esta forma, al no contar la capital con todos los recursos para poder imponerse en las provincias, las élites locales gozaban de mayor autonomía ante la falta de control. Sobre este mismo tema ha trabajado Joaquín Fernández respecto a las juntas de minería en la zona norte de Chile, demostrando que, incluso a mediados del siglo XIX, la precariedad del estado central continuaba. Véase Fernández, Joaquín, «De la colaboración con el Estado a la protesta regionalista: la Junta de Minería de Copiapó desde las Reformas Borbónicas hasta la Guerra Civil de 1859», Revista de Historia y Geografía, Universidad Católica Silva Henríquez, n. ${ }^{\circ}$ 31, Santiago, 2014.

23. Sesiones de los cuerpos legislativos (SCL), tomo II, p. 7, Decreto de 18 de mayo de 1818.

24. Véase Constitución Provisional del Estado de Chile, 1818, Preámbulo. También puede consultarse Heise, Julio, Años de formación y aprendizaje politicos 1810-1833, Santiago, Universitaria, 1978, p. 61.

25. Con relación a los títulos de nobleza véase Decreto de 15 de septiembre de 1817 en Colección de las 
vez con un carácter definitivo, que tenía entre sus fines entregarle más poder al débil y naciente Estado central chileno. Para estos efectos, el Director Supremo designó una Convención Preparatoria para sentar las bases del llamamiento y elección de un Congreso Constituyente. Sin embargo, al poco andar esta Convención se adjudicó a sí misma el carácter constituyente y se dio a la tarea de redactar la nueva Carta Fundamental, la que sería promulgada en octubre de 1822 .

El principal autor de dicho documento fue el ministro de Hacienda de la época, José Antonio Rodríguez Aldea, abogado y ex funcionario de la Corona, quien moldeó el código político de 1822 en modo similar a la constitución española de 1812, pero desde una perspectiva republicana en cuanto a las instituciones que creaba. ${ }^{26}$ Los derechos civiles y políticos clásicos estaban contemplados en su texto, así como nominalmente se establecía un sistema de separación de funciones y una clara delimitación de los poderes. No obstante, más que las maquinaciones espurias que llevaron a su promulgación, fueron otros los elementos los que condujeron al país a un punto de crisis. Por un lado, la Convención Preparatoria eligió a O'Higgins como Director Supremo por un período de seis años, como lo contemplaba el texto de la nueva carta fundamental, con posibilidad de ser reelecto por otros cuatro años. Esto implicó que O’Higgins podría gobernar por otros diez años, sumando en total catorce desde su ascensión al mando supremo en 1817, lo cual hacía pensar que el Director Supremo pretendía perpetuarse como dictador.

Pero más significativo que esto fue el hecho que los cabildos de Concepción y Coquimbo denunciaron un intento por parte de Santiago de coartar su independencia y derechos, dado que la Constitución de 1822 habría nacido viciada, prescindiendo de la voluntad de los pueblos, y además establecía una nueva estructuración administrativa del país dividida en departamentos, los cuales, junto con los cabildos se ponían bajo el control del gobierno central por medio de la figura de los llamados delegados directoriales. Estos delegados poseían la facultad de presidir y dirigir las reuniones de las municipalidades controlando directamente el gobierno local, y por extensión, amplificando la influencia de la capital sobre los gobiernos locales. ${ }^{27}$ Lo anterior, no solo reforzó los poderes del Ejecutivo, concentrando más atribuciones en manos del Director Supremo, sino que por extensión convertía a Santiago en el centro administrativo del país en desmedro de las provincias y de sus cabildos. ${ }^{28}$ Estas medidas prontamente colisionaron con toda una tradición histórica y jurídica en la que el poder municipal había gozado de un amplio marco de autonomía, y hasta en ocasiones había tenido poder suficiente para oponerse a las decisiones de gobernadores y virreyes.

leyes y decretos del gobierno desde 1810 hasta 1823, Santiago, Imprenta Chilena, 1846, p. 120. Respecto a la abolición de los escudos de armas ver Decreto de 22 de marzo de 1817 y sobre los juegos de azar véase Decreto de 7 de mayo de 1819, todos en Colección de las leyes..., cit., pp. 102 y 183.

26. Infante, Javier, Autonomía, Independencia y República en Chile, 1810-1828, Santiago, Centro de Estudios Bicentenario, 2014, p. 213. Véase también Carrasco, Sergio, Génesis y vigencia de los textos constitucionales chilenos, Santiago, Editorial Jurídica de Chile, 2002, p. 59.

27. cf. Constitución Politica del Estado de Chile de 1822, Artículos 155 y 156.

28. Jocelyn-Holt, Alfredo, La independencia de Chile..., cit., p. 297. 
En noviembre de 1822, la situación en Chile se encontraba convulsionada producto de las pretensiones de O'Higgins y sus partidarios de legitimar su permanencia en el poder a través de una nueva constitución. Si a esto sumamos una deteriorada situación económica producto del servicio de la deuda externa, la ocurrencia de un terremoto devastador que asoló buena parte del territorio central del país y una hambruna generalizada en la provincia de Concepción, entre otros problemas, se estaban dando los presupuestos ideales para una revuelta. ${ }^{29} \mathrm{El}$ intendente de Concepción, general Ramón Freire, protestó en forma airada ante el gobierno de Santiago por la inacción del mismo frente a la situación que se hacía más desesperada y que había conducido a la población de la otrora rica provincia «a comer yeguas, mulas, asnos, perros, gatos varios». ${ }^{30}$ Todo esto llevó al cabildo de Concepción y las otras municipalidades de la provincia a protestar con fuerza contra lo que veían como una franca desidia por parte de O'Higgins no solo a la situación política de la provincia, sino a su bienestar general. ${ }^{31}$ En el ínterin, ya se estaba gestando una conspiración contra el Gobierno.

El 22 de noviembre de 1822, el Intendente Freire denunció en un cabildo abierto las infracciones de ley que habría cometido O'Higgins y las violaciones a los derechos provinciales ante el concejo municipal de Concepción, el cual acordó convocar la reunión de una Asamblea de los Pueblos Libres de Concepción, cuyos representantes deberían ser electos por los cabildos de los distintos partidos de la provincia, y la cual quedó instalada el 9 de diciembre del 1822. La asamblea quedó compuesta por dieciséis diputados, de los cuales el $56 \%$ habían sido cabildantes. ${ }^{32}$

El primer acto formal de la asamblea fue declarar la ruptura del pacto social por parte de la capital y su gobierno y la consiguiente devolución de su soberanía, declarando la independencia de la provincia. ${ }^{33} \mathrm{Al}$ día siguiente, en una inflamada proclama, esta denunciaba:

29. Sobre la crisis económica y alimentaria que se vivía puede consultarse Vicuña Mackenna, Benjamín, La guerra a muerte, Buenos Aires, Editorial Francisco de Aguirre, 1972, pp. 715-755; Barros Arana, Diego, Historia general de Chile, tomo XIII Santiago, CIDBA-Universitaria, 16 Tomos, 2000, pp. 443-447; 497-562.

30. Archivo Nacional-Fondo Benjamín Vicuña Mackenna (AN-BVM), volumen 93, Carta de Ramón Freire a Bernardo O'Higgins, 4/09/1822. Véase también en el mismo volumen Carta de Ramón Freire a Bernardo O'Higgins, 20/10/1822.

31. Biblioteca Nacional-Manuscritos Barros Arana (BN-BA), Ms. BA 26, vol. 63, Proclama de la Asamblea de los Pueblos Libres de Concepción, 11/12/1822 y Archivo Nacional-Fondo Claudio Gay (AN-CG), vol. 43, Comunicaciones de la Asamblea de Concepción, 10/12/1822 y 11/12/ 1822.

32. Archivo Nacional-Fondo Varios (AN-FV), vol. 964, Invitación a la apertura de sesiones de la Asamblea de los Pueblos Libres de Concepción, 7/12/1822. Las actas de la elección de los diputados de la Asamblea, junto con algunos de sus poderes de representación pueden encontrarse en BN-BA, Ms. BA. 26, vol. 63, fs. 306-328.

33. El término independencia si bien fue usado en forma amplia en el período, se entendía como un sinónimo de autonomía y no de secesión, y refleja nuevamente el concepto histórico que se tenía de la soberanía. Frente de un gobierno devenido en ilegítimo o tiránico, la soberanía era devuelta a los estadios primordiales de decisión, los cuales se gobernaban en forma autónoma, negando obediencia a quien detentara dicho poder con anterioridad. 
Réstanos examinar ese libelo infamatorio a los Pueblos, titulado Constitución del Estado y preguntamos ¿por quién ha sido formado y con qué poderes? Se nos contestará que a la elección de esos llamados diputados de la farsal Convención no han concurrido otros electores que los elegidos por los Tenientes Gobernadores que obraron compelidos de las esquelas del Supremo para determinados individuos, por un consiguiente necesario todo es nulo y de ningún valor. ¿A vista de unas verdades tan palpables, aun trepidaremos en remover los obstáculos que se opongan a nuestra presente y futura felicidad, y a la formación de Código legal que asegure nuestros derechos? No, resueltos estamos, tiemble el opositor a tan justas medidas, y tenga advertido que el esfuerzo de los libres es de ímpetu diferente al de los mercenarios: recordemos nuestro origen araucano, y unánimes todos en seguir el ejemplo de esos esforzados guerreros aventajémoslos en el conocimiento de la Justicia de nuestra Causa y llenos de entusiasmo solo aceptemos libertad o muerte. ${ }^{34}$

El 11 de diciembre, Freire quedó instalado como Gobernador de la Provincia y comandante en jefe de su Ejército, ${ }^{35}$ el que debería utilizar para derrocar al Director Supremo en Santiago y reinstaurar el imperio de la ley. O’Higgins, por su parte, recibió prontamente la noticia del alzamiento en Concepción, notificándose por la comunicación que le enviase la asamblea provincial, indicándole que:

Desde ahora, Señor Excelentísimo se substrae esta Provincia de la obediencia de ese Gobierno convencida de su nulidad, y de los ilegítimos medios de que Su excelencia se sabe valer para perpetuar su poder contra la voluntad de todos los Pueblos del Estado (...) Los artículos constitucionales sancionados por ella nos convencen a la evidencia de que una mano parcial y poco delicada en los derechos del hombre ha querido lisonjear a Su excelencia radicando su poder, sin anuencia de los Pueblos que deben penetrarse de sus aptas o ineptas cualidades (...) Evite Su Excelencia los males consiguientes a una guerra civil; una imparcial reflexión sea el norte de sus aspiraciones. Mírense las responsabilidades que ante Dios y la Nación tendría la inatención de nuestros justificados reclamos, y de los hombres libres del Reino todo. ${ }^{36}$

En una primera instancia la asamblea ofrecía términos de negociación, incluso solicitándole a José de San Martín su mediación en el asunto, a lo que finalmente el general declinó. ${ }^{37}$ Sin embargo, la movilización preventiva del ejército de Concepción alertó a

34. Archivo Provincial de Mendoza (APM), carpeta 704, documento 70, Proclama de la Asamblea de los Pueblos Libres de Concepción, 10/12/1822.

35. BN-BA, Ms. BA 26, vol. 63, Proclama de la Asamblea General de los Pueblos, 12/12/1822. Amunátegui, Miguel Luis, La dictadura de O'Higgins, Santiago, Imprenta de J. Belín, 1855, p. 433. Véase también APM, carpeta 704, documento 69, Acta de asunción de Ramón Freire como Gobernador de Concepción, 9/12/1822.

36. APM, carpeta 704, documento 69, Oficio de la Asamblea Provincial de Concepción a Bernardo O'Higgins, 11/12/1822. Conste en la cita que todavía se utiliza la referencia «reino» para referirse a Chile.

37. BN-BA, Ms. BA 26, vol. 63, Carta de José de San Martín a la Asamblea Provincial de Concepción, 22/12/1822. Esta carta fue enviada en contestación a la solicitud hecha por la Asamblea el 14/12/1822. Asimismo, San Martín le escribió a Freire instándolo a negociar con O'Higgins y advirtiéndole: «Usted conoce el carácter de O’Higgins. Él es lleno de docilidad cuando se emplean los medios suaves. Por la inversa, es tenaz cuando se trata de emplear las amenazas. Estas son las que usted usa en su causa, no dejándole otra alternativa 
O’Higgins, forzando su primer movimiento: reprimir con fuerza cualquier conato contra su autoridad. Para estos efectos, envió cerca de 1200 hombres al mando del general Luis de la Cruz. No obstante, al poco andar, en las inmediaciones de Rancagua las tropas del gobierno se rebelaron contra su comandante, al cual le dieron la opción de seguirlas y unirse a Freire o volver a Santiago. De la Cruz, honrando la amistad y confianza de O’Higgins, volvió a Santiago como portador de las malas noticias. ${ }^{38}$

Por otra parte, el 20 de diciembre de 1822 un cabildo abierto en La Serena, reunido en sesión extraordinaria, proclamaba la creación de una Asamblea Provincial de Coquimbo, con el fin de que esta representase los derechos de la Provincia. Esta quedó compuesta de nueve miembros, de los cuales el $89 \%$ habían sido miembros de cabildo. ${ }^{39}$ Coquimbo siguió el mismo camino que Concepción: declarar la independencia de la Provincia frente al gobierno central, reclamando haberse devuelto la soberanía a sus detentores originales dadas las infracciones cometidas por Santiago. A los pocos días, la misma asamblea le comunicaba a O'Higgins:

Los pueblos que consultan su bien no pueden equivocarse y si yerran no hay quien tenga facultades de formar su resolución. Ellos son soberanos y dueños absolutos de su voluntad, si esta ha sido enajenada por hombres corrompidos de cuanto hiciesen es nulo, ni da más propiedad que la que adquiere el detractor (...) Bajo de estos principios cree Coquimbo hallarse en el caso de representarle a Su Excelencia la usurpación de sus derechos: al efecto ha nombrado una asamblea provisoria compuesta de suplentes que representen los pueblos de la provincia, ínterin estos eligen sus diputados y encargada a llevar a su término el reclamo tomando las más prudentes providencias. (...) Solo queremos que se fijen las bases de nuestra libertad por una representación legítima, quitando de antemano los obstáculos que hasta aquí la han oprimido. Parece que Concepción abriga los mismos pensamientos y si la capital estuviera desunida de la fuerza, seguiría nuestra marcha de acuerdo con aquella benemérita provincia, mientras tanto Vuestra Excelencia termina tan perjudiciales diferencias. ${ }^{40}$

Asimismo, siguiendo los pasos dados por Concepción, Coquimbo envió un pequeño destacamento armado contra Santiago, comandado por Miguel Irarrázaval, con el fin de auxiliar a Freire. ${ }^{41}$

Frente al descalabro de sus fuerzas militares, O'Higgins envió emisarios para negociar con Freire, ${ }^{42}$ pero cualquier posibilidad de acuerdo se desmoronó una vez que las

que su separación del mando con deshonor». Véase también BN-BA, rollo 26, tomo 63, Carta de José de San Martín a Ramón Freire, 23/12/1822.

38. Amunátegui, Miguel Luis, La dictadura ..., cit., p. 427

39. Valencia Avaria, Luis, Anales de la República de Chile, Santiago, Andrés Bello, 1986, Acta de instalación de la Asamblea Provincial de Coquimbo, 20/12/1822, p. 25. Ver también Archivo Nacional-Intendencia de Coquimbo (AN-IC), vol. 17, Proclama a los pueblos de Coquimbo, 20/12/1822 y AN-FV, vol. 815, Proclama de la Asamblea de la asamblea de la capital del norte a los pueblos que la constituyen, 23/12/1822.

40. AN-IC, vol. 17, Oficio de la Asamblea Provincial de Coquimbo a Bernardo O'Higgins, 26/12/1822.

41. Amunátegui, Miguel Luis, La dictadura ..., cit., p. 442.

42. Los emisarios de O’Higgins fueron Miguel Zañartu, José Gregorio Argomedo, Salvador de la Cavare- 
asambleas de Coquimbo y Concepción, temerosas de que el Director Supremo recibiese auxilios desde Mendoza y San Juan, exigieron su renuncia, aun cuando el apoyo nunca se verificó. ${ }^{43}$ Con poco más que sus partidarios más cercanos, O’Higgins tuvo que enfrentar un conato revolucionario en Valdivia y otro más grande en Santiago, que terminó con su abdicación el 28 de enero de 1823 y la inmediata creación de una Junta de Gobierno compuesta por Fernando Errázuriz, José Miguel Infante y Agustín de Eyzaguirre, todos antiguos miembros del cabildo de Santiago. ${ }^{44}$

La Junta de Santiago se proclamó como el gobierno provisional del país hasta que se convocase a elecciones ese mismo año. ${ }^{45}$ Sin embargo, ni Coquimbo ni Concepción estaban dispuestos a reconocerla como el gobierno general de Chile, ${ }^{46}$ pero solo como el gobierno de la Provincia de Santiago. ${ }^{47}$ Las asambleas de Concepción y Coquimbo insistieron que Santiago carecía de cualquier mandato, derecho o autoridad para arrogarse tales atribuciones. Coquimbo contestó a la Junta de Santiago que al estar

(...) autorizada[la Junta] por la sola abdicación del ex Director se titula de todo el Estado, y resuelve ya en materias anexas a la representación general cuando cabalmente carece de todo aquel (...) Tan convencida se halla la provincia de Coquimbo de la verdad que para no equivocar las ideas de libertad ni adquirir propensión a la anarquía, en sus votos proclamados el 20 de diciembre (y que juró sostener su sangre) solo reclama sus derechos, sin contradicción a la disposición de quien se los usurpaba, por el contrario la Junta de Santiago quiere hacer concebir que los pueblos han adquirido su libertad con haber quitado el mando al director O'Higgins, y no advierten que el sostén de esta será el que cause la anarquía si no son tocados con tiempo del desengaño. ${ }^{48}$

da y José María Astorga. Ver Archivo Nacional-Ministerio del Interior (AN-MI), vol. 11, Comunicaciones de la diputación diplomática del gobierno directorial, 23/01/1823 al 29/1/1823.

43. AN-FVM, vol. 93, Carta de José Ignacio Zenteno a Bernardo O'Higgins, 27/12/1822. Zenteno escribía: «Es muy consiguiente que la anarquía devore a Concepción: yo a lo menos no veo allí una cabeza capaz de dar un impulso coordinado, y esto abre a V. un campo inmenso para obrar suavemente en la pacificación. Mucho he celebrado el ofrecimiento de Mendoza, y si fuera que V. lo admitiría. Esas son tropas suizas, que no tienen más partido que el del gobierno». Por su parte, la Asamblea de Coquimbo, previendo las maquinaciones en su contra y de Concepción, le comunicó a esta última que: «Como la ambición del déspota directorial extiende sus miras opresivas hasta lo sumo, toca todos los recursos para sumergir a los libres en los más recónditos de su negra intención, valiéndose de sus satélites que siguen sus mismas huellas (...)» AN-IC, vol. 2, Comunicaciones de la Asamblea de Coquimbo con la Asamblea de Concepción, 15/01/1823. Véase también AN-IC, vol. 27, Comunicaciones de la Junta de la Provincia de San Juan a la Asamblea de Coquimbo, 16/01/1823. La respuesta de Mendoza se encuentra en el mismo volumen con fecha 22/01/1823.

44. Archivo Nacional-Intendencia de Concepción (AN-ICON), vol. 32, Actas de Valdivia en desconocimiento de la autoridad del gobierno de Santiago, 25/01/1823 y 26/01/1823 y BN-BA, Ms. BA 26, Acta de abdicación del mando del Supremo Director, 28/1/1823 y AN-MI, vol. 9, Circular enviada por la Junta de Santiago a los pueblos de Chile, 30/1/1823.

45. BN-BA, Ms. BA 26, vol. 63, El gobierno a los pueblos. Chilenos, 5/2/1823.

46. AN-MI, vol. 46, Comunicación de la Junta de Santiago a Ramón Freire, 6/2/1823.

47. Correspondencia seguida entre la Junta Gubernativa y el Mariscal de Campo D. Ramón Freire, Santiago, Imprenta Nacional, 1823, pp. 8-14.

48. AN-IC, vol. 2, Comunicación de la Asamblea de Concepción a la Junta de Santiago, 3/2/1823 y AN-IC, vol. 7, Nota en respuesta al oficio de la junta de Santiago que mandó a esta asamblea con fecha 25 de febrero pasado. 
Por su parte, Concepción hizo lo propio, indicándole a la Junta de Santiago que:

Cuando la Provincia de Concepción ha proclamado su Libertad, se resolvió unánime a no admitir otro gobierno que el que quede constituido por la voluntad general libremente manifestada (...) Así es que no se da una razón para que legítimamente pueda titularse Junta Gubernativa del Estado como lo vemos en la práctica, pues ni aun se halla adornada de los votos de los partidos de esa provincia (...). ${ }^{49}$

De esta forma, y por conducto de sus representantes en las respectivas asambleas provinciales, los cabildos provinciales de Coquimbo y Concepción exigieron de Santiago la formación de un Congreso de Plenipotenciarios que asegurase, en primer término, la igualdad de las provincias en la creación de lo que se denominó un gobierno general, con el fin de reunir y reorganizar a las provincias en el ejercicio de su soberanía como constituyentes de la República de Chile, así como también para sentar las bases de la convocatoria a un Congreso Constituyente.

Santiago se negó terminantemente, considerando que cualquier dilación perjudicaba la continuidad y sobrevivencia de la República, siendo imperativo que ambas asambleas reconocieran a la Junta como el gobierno central del país. ${ }^{50}$ Pero Santiago carecía de la fuerza política y especialmente de la militar como para imponerse decididamente sobre las pretensiones provinciales. Coquimbo y Concepción forzaron a Santiago a crear su propia asamblea provincial ${ }^{11}$ con el fin de que ésta nombrase a un individuo que la representase en un Congreso de Plenipotenciarios, ${ }^{52}$ el cual sentaría las bases de un ordenamiento constitucional provisional que llevó el título de Reglamento Orgánico y Acta de Unión. Esta Acta de Unión declaraba que el Estado de Chile era «uno e indivisible», pero al mismo tiempo estipulaba que la nación chilena se organizaba soberanamente por medio de sus respectivas asambleas provinciales. ${ }^{53}$ Por otra parte, el Congreso de Plenipotenciarios también se encargó de elegir un Director Supremo provisional, cuyo nombramiento recayó en Ramón Freire. ${ }^{54}$ Finalmente, correspondió a esta asamblea ordenarle a Freire que convocase a la reunión de un nuevo Congreso, con el carácter de constituyente, algo que Freire hizo diligentemente apenas asumió el mando y que quedó instalado el 16 de agosto de 1823.

En diciembre de 1823, una nueva constitución había sido promulgada. Una administración recargada de magistraturas, con un exagerado sistema de pesos y contrapesos

49. AN-IC, vol. 2, Comunicaciones entre la Asamblea de Coquimbo y la de Concepción, 8/02/1823.

50. AN-FV, vol. 972, Oficio de la Junta de Gobierno de Santiago, 25/3/1823.

51. La existencia de esta asamblea fue efímera, sesionando solamente entre el 29/03 y el 3/04 de 1823. Solo se reunió para elegir al representante de Santiago al Congreso de Plenipotenciarios, para luego auto disolverse.

52. Estuvo formado por Juan Egaña representando a Santiago, Manuel Novoa por Concepción y Manuel Antonio González por Coquimbo.

53. Reglamento orgánico y Acta de Unión, 30/03/1823 (Preámbulo).

54. SCL, vol. VIII, p. 75. 
complementaba un esfuerzo pedagógico de corte ilustrado y republicano, enfocado en la creación de una «aristocracia cívica». ${ }^{55}$ Este era el sello que el redactor de la nueva Carta Fundamental, Juan Egaña, había tratado de imprimir en ella. Pero incluso Egaña, quien había defendido las pretensiones de Santiago en el Congreso de Plenipotenciarios y favorecía la implantación de un régimen unitario, había caído en la cuenta de que el nuevo orden político del país no podía pasar por alto el tópico de la autonomía provincial frente al gobierno central. Las provincias, por su parte, querían prevenir una posible preeminencia de Santiago y la vulneración de sus intereses, estableciendo un equilibrio de poder entre ellas y la capital, insistiendo en la necesidad de proteger sus «derechos naturales».56

Para complacer a las asambleas, Egaña les otorgó a los cabildos un grado relativo de autonomía. ${ }^{57}$ Asimismo, creó un símil de las asambleas provinciales, esta vez dentro del orden constitucional, con el nombre de Consejo Departamental, ${ }^{58}$ presidido por el respectivo gobernador y por vocales designados por las delegaciones al interior del departamento. ${ }^{59}$ Esto era un compromiso en favor de las de las élites provinciales, representadas ahora doblemente en los cabildos, así como en sus respectivos consejos. Sin embargo, al margen del texto constitucional, los cabildos se reservaron prácticas y mecanismos paralegales como la entrega de instrucciones en la forma de mandatos imperativos, y poderes a los diputados al Congreso con el fin de resguardar su influencia en el sistema político. ${ }^{60}$

\section{Entre la autonomía provincial y el federalismo: 1825-1828}

\section{Crisis de autoridad y representatividad}

La crisis que derivó en el colapso de la administración O’Higgins dejó entrever ciertas fisuras en el entramado de la naciente república chilena. Si bien hubo consenso temprano sobre la forma de gobierno, era evidente que no existía acuerdo sobre la forma de su Estado, y esto pareciera desvirtuar, en parte, el relato de la primera historiografía nacio-

55. Errázuriz, Isidoro, Historia de la administración Errázuriz, Santiago, Imprenta General de Prisiones, 1935, p. 221 y Castillo, Vasco, La creación de la República. La filosofía pública en Chile 1810-1830, Santiago, LOM, 2009, pp. 133 y ss.

56. AN-IC, vol. 2, Comunicación entre la Asamblea de Coquimbo y la Asamblea de Concepción, 24/01/1823.

57. Constitución politica y permanente del Estado de Chile, 1823, artículos 215 y ss.

58. Constitución política y permanente del Estado de Chile, 1823, Artículos 208-214. En la sesión del 25/12/1823, el capítulo de Régimen Interior que incluía los Consejos Departamentales fue aprobado por unanimidad en el Congreso. SCL, vol. VIII, pp. 626-628.

59. Constitución política y permanente del Estado de Chile, 1823. Los artículos 210 a 212 determinaban las funciones del Consejo Departamental.

60. Ver González Echenique, Javier, «Un estudio de influencias doctrinarias en la Independencia: El concepto de diputado o representante popular. 1810-1828», Historia, n. ${ }^{\circ}$ 6, Santiago, 1967, pp. 143-144. Ejemplos documentales de dichas instrucciones pueden encontrarse en AN-IC, vol. 7, Instrucciones que se ban dado al diputado de Coquimbo para Santiago don Manuel Antonio González, 4/03/1823, AN-IC, vol. 526, Oficio de Juan Fariñas a la Asamblea de Coquimbo, 23/06/1827; AN-IC, vol. 1, Oficio de la Asamblea de Coquimbo a la Asamblea de Concepción, 8/08/1825. 
nal de que la preponderancia de Santiago por sobre el resto de las ciudades y provincias del país se presentaba inconmovible, salvo contadas excepciones. Pero la verdad sea dicha, los hechos parecen demostrar lo contrario. Aún más, esos bemoles en el curso de la formación del Estado en Chile no eran solamente ejemplos de la transición política, sino que eran el fiel reflejo de una tradición centenaria que colisionaba en forma violenta con las ideas de una revolución que, en su discurso, conminaba a destruir el Antiguo Régimen, sustituyéndolo por uno nuevo.

Pese a haberse dictado una nueva constitución, bajo los parámetros que las mismas provincias habían impuesto a Santiago, el panorama político en Chile entre 1824 y 1825 demostraba que la crisis continuaba. Suspendida la Constitución de 1823 por impracticable a los seis meses de entrada en vigor, en diciembre de 1824 el Congreso la derogaba completamente y se declaraba constituyente, ${ }^{61}$ aun cuando el mismo Congreso era cuestionado acerbamente, por una presunta inacción para resolver temas urgentes que aquejaban al país: servicio de la deuda, crisis económica, inestabilidad política. ${ }^{62}$ El otrora popular Ramón Freire se encontraba enfrentado al faccionalismo de los grupos al interior del Congreso e incluso en su misma administración. Así entonces, el gobierno central se vio exangüe frente al resto de las provincias, que miraban con preocupación el estado de cosas en la capital.

La primera manifestación de descontento provino de Concepción. El 20 de abril de 1825 se reunió un cabildo abierto que, junto con revocarle sus poderes de representación a sus diputados en Santiago, conminó al resto de los pueblos de la provincia a seguir el mismo ejemplo y enviar diputados a Concepción para que «(...) formen una asociación o asamblea, con el solo objeto de acordar lo conveniente en las circunstancias (...)». ${ }^{63} \mathrm{~A}$ las pocas semanas, todos los partidos de la provincia retiraron sus poderes y representantes, mientras que una nueva Asamblea Provincial de Concepción abría sus sesiones el 23 de mayo de $1825 .{ }^{64}$

En Coquimbo, por otro lado, se dio una circunstancia similar. El 22 de mayo de 1825 un cabildo abierto, presidido por el intendente Francisco Antonio Pinto, retiraba los poderes a sus diputados e invocaba los derechos de Coquimbo para:

(...) reunir y formar su legislatura provincial, que dicte las reglas por las cuales llegue el país a su más alto grado de prosperidad, que provea a todo lo económico y particular de la provincia,

61. Véase SCL, vol. X, p. 190 y Ossa, Juan Luis, «La actividad política de Francisco Antonio Pinto: 1823 1828. Notas para una revisión biográfica», Historia, n. ${ }^{\circ}$ 40, vol. 1, Santiago, 2007, p. 102.

62. Zañartu, Miguel; Cuadro Histórico del Gobierno del Señor Freire, Lima, s/i, 1826, pp. 9 y ss. Por otro lado, el cónsul británico C.R. Nugent indicaba algo similar en un oficio al Secretario de Estado del Foreign Office George Canning. Ver National Archives-Kew (NAK), Oficio de Cristopher Nugent al Secretario de Estado del Foreign Office, FO 16/1, 23/02/1825.

63. SCL, vol. XI, p. 215. Se reiteraba tanto en el art. $3 .^{\circ}$ como en la conclusión del acta que la Asamblea se subordinaría al gobierno central en Santiago, cosa que quedó solo en el papel.

64. SCL, vol. X, sesiones de 28 y 29/04/1825, pp. 206-216, y de 4/05/1825, pp. 223-225. Véase también en el mismo tomo los anexos 383-385, pp. 266-267. Véase también AN-FV. vol. 445, Actas de sesiones de la Asamblea Provincial de Concepción. 
que revise las leyes fundamentales de la Nación, y en cuyo cuerpo deliberativo se vea el voto uniforme de sus ciudadanos» (...), justificando dichos pasos por la desorganización actual de la República, que se mira sin instituciones ni más garantías que la buena fe del Supremo Director; la marcha lenta y tardía del Congreso; la separación de los diputados de Concepción y la mayor parte de Coquimbo; el incremento que han tomado los partidos, todos son causales que obligan a este pueblo a mirar por sus intereses recíproco, y convocar a la mayor brevedad su asamblea provincial. ${ }^{5}$

Nuevamente puede verse el resurgir de la tradición autonómica provincial, la misma que en 1822 negó la legitimidad del gobierno de O'Higgins ahora hizo algo similar, al desconocer, apenas veladamente, la legitimidad de los poderes del Estado encargados de la administración y la creación de las leyes. Pero también aparece una práctica que solo se explica si se tiene presente la pervivencia, a lo menos parcial, de la noción proveniente del ideario jurídico del Antiguo Régimen. Ante la vacancia del poder, la soberanía retornaba a los pueblos, quienes podían en el intertanto decidir el curso de acción más conveniente para los intereses de sus provincias. Sin embargo, es necesario añadir otro elemento que tiene que ver con la representación: los mandatos imperativos. De acuerdo con esta doctrina, el diputado obraba solo como un depositario provisional cuyos poderes eran esencialmente revocables por parte de los detentores primarios y originarios de la soberanía, forma, por lo demás, en que se había concebido la representación en Chile desde la creación del primer Congreso Nacional en 1811, y que había continuado luego de la declaración de la independencia.

Los cabildos elegían a los diputados para luego otorgarles poderes de representación e instrucciones, a veces pormenorizadas y otras veces más generales. Esta noción implicaba que los pueblos, entendidos como fuente de la soberanía, no habían hecho cesión de su poder en forma ilimitada e irrestricta, ya que su representante seguía estando ligado a sus electores y respondía materialmente ante ellos o ante la corporación que los representaba localmente, por el cumplimiento de sus instrucciones. ${ }^{66}$ No obstante, a diferencia de lo acontecido en el período 1822-1823, esta vez no bastaría con asegurar los equilibrios entre las provincias intermediando una figura carismática como lo fue Freire en su momento, ni tampoco la dictación de una Carta Fundamental que diluyera el poder del Estado central o que se asegurase cierta autonomía de las instituciones de gobierno local, como lo hiciera la constitución de Egaña, sino la creación de un sistema político-administrativo que reconociese la existencia de las asambleas provinciales, y que las dotara de un marco de acción amplio, asegurando con su continuidad las aspiraciones locales.

65. SCL, vol. X, p. 257. La Asamblea Provincial de Coquimbo abrió sus sesiones el 26/06/1825. Véase Archivo Nacional-Fondo Cabildos y Municipalidades (AN-FCM), vol. 2, Actas de sesiones de la Asamblea Provincial de Coquimbo.

66. González Echenique, Javier, «Un estudio...», cit., p. 146. A partir de 1825 el gobierno nacional intentó prohibir el otorgamiento de instrucciones a los diputados encontrando resistencias por parte de las autoridades provinciales a más de la falta de cooperación de los cabildos, quienes eran los que daban las instrucciones. Ver AN-IC, vol. 2, Oficio de la Asamblea provincial de Coquimbo al Director Supremo del Estado, 25/08/1825. 
La crisis de autoridad del Estado chileno permitió la irrupción en la escena política de nuevas propuestas sobre la forma que debía tener el Estado y la relación de éste con las partes integrantes del país sometidas a su administración. El modelo federal, propalado entre otros, por José Miguel Infante, prometía satisfacer las demandas por autonomía e igualdad en la representación por parte de las provincias, y el mismo Infante, en su defensa de la federación, proclamaba que:

(...) las provincias siempre se han quejado de que, en la capital de Santiago, hay un espíritu de capitalismo; yo creo que injustamente ya hieren al pueblo de Santiago, porque el espíritu de capitalismo solo ha existido en los gobernantes y sus prosélitos y no en Santiago (...) Cuando las provincias nos dicen: «Queremos federación», nos dicen: «Queremos nombrar nuestros gobernadores, queremos tener nuestras asambleas, para que arreglen lo interior de la provincial». ¿Puede haber una pretensión más justa? ${ }^{67}$ [destacado por el autor]

Parecía que la simiente para la federación en Chile requería de un mero acto de voluntad. Pero antes de que el mismo Infante tocara a rebato por la causa federal, ya el gobierno de Freire había dado pasos en dicha materia. El 30 de noviembre de 1825, a instancias del ministro del Interior Joaquín Campino, el Consejo Directorial que gobernaba el país en ausencia del director Freire ${ }^{68}$ promulgó un Reglamento provisorio para la administración de las provincias, que en sus 50 artículos creaba una nueva división política administrativa para Chile aumentando a ocho la cantidad de provincias en que se dividía el país y otorgaba amplias atribuciones a las asambleas provinciales, ordenando la creación de cinco nuevas asambleas, por cada una de las nuevas provincias creadas. ${ }^{69}$

Sin embargo, parafraseando a Simon Collier, la utopía federal también sería insuficiente para consolidar en forma exitosa un modelo de institucionalización en Chile. ${ }^{70}$ No existía uniformidad en cuanto a la aplicación del sistema. Santiago se negaba tajantemente advirtiendo que miraba con horror «cuanto manifieste tendencia o prerrogativas exclu-

67. SCL, vol. XI, p. 369. El destacado es mío.

68. El 12 de noviembre de 1825, Ramón Freire instaló un Consejo Directorial, para que administrase el país a su nombre mientras comandaba su segunda expedición contra Chiloé. El Consejo estuvo formado por José Miguel Infante, como su presidente, secundado por Joaquín Campino (ministro del Interior y de Relaciones Exteriores), José Manuel Gandarillas (Hacienda) y José María Novoa (Guerra y Marina), aunque su composición varió con el tiempo. Ejerció sus funciones entre el 15 de noviembre de 1825 y el 7 de marzo de 1826, fecha en que Freire reasumió como Director Supremo. Parte de las actas del Consejo Directorial se encuentran en Archivo Nacional-Consejo de Estado (AN-CE), vol. 1.

69. Sanhueza, María Carolina, «La primera división político-administrativa de Chile, 1811-1826», Historia, vol. 41, n. ${ }^{\circ}$ 2, Santiago, 2008, pp. 478-479. Respecto a la creación de nuevas asambleas véase el Reglamento provisorio en Briceño, Ramón, Memoria bistórico-critica del derecho público chileno, Santiago, Imprenta de Julio Belín, 1849 , pp. 435-438. A este reglamento le seguiría un decreto que modificaba la demarcación anterior de las provincias, pero mantenía su número, fechado el 31/01/1826 y finalmente una ley definitiva que sancionaba la delimitación de fecha 28/08/1826. Ver Sanhueza, María Carolina, «La primera división...», cit., pp. $482-482$ y 487.

70. Collier, Simon, Ideas and politics..., cit., p. 310. 
sivas, y que no procedan en una forma igual y sólidamente Nacional». ${ }^{71}$ Concepción parecía mostrarse más moderada buscando asegurar el reconocimiento legal de la igualdad entre las provincias, radicando en las asambleas funciones de orden local. Sobre el particular la Asamblea de Concepción indicaba que:

En el término de seis meses a lo más formarán un proyecto de constitución en el cuál la Nación se denominará República de las Provincias Unidas de Chile. Se ratificará la división del estado en las ocho Provincias, en los términos que la ha hecho el Gobierno. Tendrá cada una el propósito de tener asamblea, cuyas atribuciones serán entre otras, nombrar los senadores que deben componer una parte de las siguientes legislaturas. Hacer y proponer a la legislatura los proyectos de ley y reglamentos que crea conducentes al fomento de las respectivas Provincias con relación a sus ventajas locales. Firmar y remitir al senado la lista de elegibles para los empleos nacionales y provinciales. ${ }^{72}$

Pero Coquimbo parecía tener una postura más radical, partidaria sino del federalismo, por lo menos de una amplísima autonomía a nivel local. A principios de julio de 1825 la Asamblea de Coquimbo promulgó una Ley Fundamental para la provincia, que indicaba en uno de sus artículos: «Art. 6. ${ }^{\circ}$ La asamblea se reserva la facultad de revisar la Constitución Política de la Nación, y aquellas leyes que tengan el carácter de fundamentales para ratificarlas o no, si no lo estimase conveniente». ${ }^{73}$ A mayor abundamiento, a los pocos días la misma asamblea advertía al gobierno de Santiago su convicción en proteger por todos los medios posibles los derechos de la provincia y su autonomía recientemente alcanzada:

(...) sí una confianza ciega sugiriera a Santiago la imprudente determinación de desatender a nuestras justas e invariables reclamaciones, que no se olvide de lo que fuimos otras veces, y que absolutos en el círculo de nuestro territorio, sabremos defender con energía nuestras propiedades y nuestra libertad (...) fuera de esto preferimos cualquier estado de existencia política, a la ignominiosa degradación de vernos esclavos del insano capricho de ese odioso nombre de Capital, que trata de sumergirnos en el abismo. ${ }^{74}$

Los hechos consumados, tanto en Coquimbo como en Concepción, forzaron la mano de Freire para inclinarse, o por lo menos someterse, al impulso de los federalistas. Su posición política, por lo demás, era extremadamente delicada, siendo presionado en el interior por las disrupciones administrativas, como también desde el exterior, ya fuera por la

71. Biblioteca Nacional-Sala Medina (BN-SM), rollo 128, A las honorables asambleas de Concepción y Coquimbo, 12/09/1825.

72. AN-FV, vol. 445, Acuerdo de la Asamblea Provincial de Concepción, 12/05/1826. Ver también sobre las atribuciones de los gobernadores provinciales y las asambleas respecto al gobierno central en AN-CE, vol. 1, Oficio de Manuel José Gandarillas al Consejo Directorial, 20/1/1826 y Acta del Consejo Directorial, 17/1/1826.

73. AN-IC, vol. 521, Artículos de ley fundamentales de la Asamblea de Coquimbo, 1/07/1825.

74. AN-FCM, vol. 1, Oficio de la Asamblea de Coquimbo al Director Supremo Ramón Freire, 18/07/1825. Véase también SCL, vol. XII, p. 30, Manifiesto que hace la Asamblea de Coquimbo A los pueblos de la República sobre la inteligencia de sus instrucciones federales a los diputados de la provincia en el Congreso Nacional de 1826. 
insistencia de los acreedores británicos en el pago del servicio de la deuda chilena, o por la insistencia de Simón Bolívar para que Chile anexase Chiloé eliminando el último baluarte español en América del Sur. ${ }^{75}$ Mediando su exitosa expedición a Chiloé, finalizada en enero de 1826, Freire convocó a la elección de un congreso constituyente, el cual se reunió el 4 de julio de 1826 en Santiago, con el fin de dotar a Chile de una forma de Estado definitiva, de la mano de la promulgación de una constitución. Fue en este momento que el Director Supremo decidió dar un paso al costado, renunciando al mando de la nación, el cual fue asumido por el almirante Manuel Blanco Encalada, ahora en calidad de presidente de la República. ${ }^{76}$

Abiertas las sesiones del nuevo congreso, el incremento de la popularidad del federalismo quedó de manifiesto en el éxito contundente obtenido en las urnas, que les permitió contar con 30 de 56 diputados, quienes compartían el ideario federal. Así entonces entre julio y octubre de 1826, comenzó un frenesí legislativo en que se promulgó una serie de leyes que instauraban y organizaban el régimen federal en Chile. El 7 de julio se designó una comisión compuesta por José Ignacio Cienfuegos, Diego Antonio Elizondo, Juan Farías, José Miguel Infante, Francisco Ramón Vicuña e Isidro Pineda, con el mandato de elaborar una nueva constitución, y para diciembre de 1826 dicho proyecto constitucional federal ya era discutido en las salas del Congreso, inspirado en las experiencias de Estados Unidos de América y México. ${ }^{77}$

¿Qué explicación se puede dar a la repentina popularidad del federalismo? En parte, el federalismo parecía constituirse en una respuesta para superar la tensión entre las doctrinas modernas de representación política y la tradición de autogobierno local heredada del Antiguo Régimen, estimulando y ampliando la participación ciudadana como una vía idónea para salvaguardar las libertades individuales, así como también los intereses de las élites locales, de alguna forma vistiendo con ropajes nuevos y revolucionarios, instituciones y prácticas tradicionales. ${ }^{78}$ Pero también el federalismo pareció ser una ex-

75. Carta de Simón Bolivar a Manuel Blanco Encalada, 16/10/1825 en Villamil Concha, Enrique, «Vida de Don Manuel Blanco Encalada», Revista Chilena de Historia y Geografía, Año IX, tomo XXXVI, Santiago, 1919, p. 261. Véase también las tratativas del gobernador Antonio de Quintanilla con el Foreign Office británico para incorporar Chiloé al dominio inglés. Ver NAK, FO16/1, Oficio de Cristopher Nugent al Secretario de Estado del Foreign Office. Véase también Webster, Sir Charles K., Britain and the Independence of Latin America: 18121830: select documents from the Foreign Office archives, Londres, Oxford University Press, 1938, p. 360 y Valenzuela, Renato, Bernardo O'Higgins. El estado de Chile y el poder naval en la independencia de los países de América del Sur, Santiago, Andrés Bello, 1999, pp. 242-243. Véase también Archivo Nacional-Ministerio de RR. EE. (AN-MRE), vol. 1, Oficio del ministro del Interior de Chile al del Perú, 31/08/1825.

76. SCL, vol. XII, pp. 43-48.

77. SCL, vol. XII, p. 92. Respecto al proyecto constitucional este se encuentra en SCL, vol. XIV, pp. 75 85. Sobre la discusión del mismo véase en el mismo volumen pp. 166, 272, 275-285, 295, 312, 338, 343-345, $351-353,374-377,381-386,393,410,412-418$. El proyecto no solo contemplaba la creación de una estructura federal para el país, con sus respectivas instituciones, sino que hacía descansar el gobierno local en las asambleas provinciales, presididas por su respectivo intendente, siguiendo de esta forma el reglamento de noviembre de 1825, elevando el reconocimiento de las asambleas a nivel constitucional.

78. Collier, Simon, Ideas and politics..., cit., p. 288. cf. SCL, vol. XI, p. 337, 369-370 y SCL, vol. XII, p. 103. La idea sobre la tensión está bien desarrollada en Castillo,Vasco, La creación ..., cit., p. 152. 
presión de desconfianza frente a las tendencias a establecer un gobierno fuerte y centralizador. Esto fue manifestado abiertamente por la Asamblea de Coquimbo indicando que no había

(...) otro arbitrio que privar al Gobierno de esa amplitud de poder con que le reviste la unidad; de lo contrario, nos veremos a cada instante en la necesidad de hacer una revolución para quitar el mando a un déspota que se complace en el sacrificio de sus conciudadanos». ${ }^{79}$ Asegurada entonces la libertad, al decir de José Ignacio Cienfuegos, «¿a qué director o presidente podría ocuparle por un momento la idea o imaginación de oprimir las provincias, existiendo ellas separadas y gobernadas por sí? Todo ha de ser libre en los pueblos, de suerte que todas las partes de Chile respiren libertad (...). ${ }^{80}$

Pero, así como el federalismo tuvo partidarios apasionados, detractores tenaces también los hubo, como Jean Joseph Dauxion Lavaysse, un naturalista francés contratado como director del Museo de Historia Natural, quien en su folleto Del Federalismo y la Anarquía denunciaba como el federalismo había arrasado la América Española:

De nada les sirve el ejemplo de los pueblos colombianos, entre los cuales el sistema federal fue la señal de las insurrecciones militares, y de las guerras civiles, al grado que hubieran sido conquistados por los españoles, si no hubiesen conseguido ahogar sus locas, bárbaras, ridículas y desorganizadores juntitas, congresitos y republiquetas provinciales, para volver al sistema de UNIDAD representativa y ejecutiva. ¿No les horrorizarán, no les avergonzarán, no les dará asco, aquellas provincias de la Plata, tan prósperas antes de la revolución y que durante los cuatro años que las gobernó el general Belgrano hicieron tan rápidos progresos en la carrera de la civilización? ¿Da lástima ver aquellos cabildos, aquellas Juntitas, aquellas republicallas (sic), metamorfoseadas en casas de San Andrés, y en aduares de salvajes caníbales, al instante mismo que aquella caja de Pandora el federalismo, reventó entre aquellos pueblos? No, no los horroriza, pues quieren ellos que sobre aquella escala resbalosa (sí, resbalosa de sangre, de crímenes, de estupros, de lágrimas, etc.) pase Chile, para subir a la perfección ideal de nuestros salvajes Dracos. ${ }^{81}$

Por su parte, los Egaña -Mariano y Juan-, también se pronunciaban abiertamente en contra del sistema federal. Juan Egaña tuvo una notable polémica, primero con el ministro plenipotenciario de los Estados Unidos, Samuel Larned, y luego trascendiendo el debate fuera de las fronteras de Chile, enfrentando como contradictor a Vicente Rocafuerte. ${ }^{82}$ Mariano por su parte escribía una carta a su padre en noviembre de 1826 , desbordante de ironía:

79. SCL, vol. XII, p. 31.

80. SCL, vol. XII, p. 55.

81. Dauxion Lavaysse, Jean Joseph (Amerícola), Del Federalismo y la Anarquía, Santiago, Imprenta Nacional, 1823 , pp. 18-19.

82. Egaña, Juan, Memorias políticas sobre las federaciones y legislaturas en general y con relación a Chile, Santiago, Imprenta de la Independencia, 1825 y Larned, Samuel, Observaciones en contestación a un artículo 
Se ha publicado la ley de la federación expedida el 11 del mismo, y se indica el nombramiento del señor Infante para presidente de la República y del señor Pinto para Vicepresidente. Viva, viva, viva, viva, viva la Patria (...) Había tenido un consuelo al ver en las gacetas de Buenos Aires la discusión sobre si su gobierno debía ser central o federal. Aquí ha sido aplaudida la sabiduría y prudencia del debate y la resolución expedida por una mayoría tan notable. Creía como era natural que nuestros nefandos monos la imitasen; pero se anticiparon porque es eminente el tino que tienen para hacer mal: huyen hasta de las casualidades que se lo pudieran impedir. 36 gavilanes han fallado la suerte de Chile (...). ${ }^{83}$

En el interior del Congreso, otros tantos se opondrán al régimen federal por considerar que sobrecargaba excesivamente el erario, llenando al país de instituciones administrativas redundantes e innecesarias en cada una de las provincias del país. «¿Qué resultará del establecimiento de la federación? — se preguntaba retóricamente el diputado Domingo Eyzaguirre- El desorden, la desorganización y la miseria de todos los pueblos; era necesario buscar una piedra filosofal que nos enseñase a sacar recursos de donde absolutamente se carece de ellos». ${ }^{84}$

La discusión aparentemente interminable al interior del Congreso y el disenso en el modo de obrar entre las asambleas provinciales de Santiago, Coquimbo y Concepción comenzó por debilitar el impulso federalista. Por otra parte, algunas provincias vieron la implantación del régimen federal como una imposición desde Santiago. Si bien el régimen parecía asegurar sus libertades por medio de la devolución de parte de su soberanía a instituciones locales, las cinco provincias recién creadas eran muy dispares en cuanto a recursos y población comparadas con las tres provincias principales. Esto conspiraba entonces contra el sostenimiento del régimen, tal y como Domingo Eyzaguirre protestó en su momento. Sumado a esto, un aumento en el descontento entre algunos sectores del ejército, así como en la opinión pública, causó la renuncia del almirante Blanco Encalada en septiembre de 1826. En su reemplazo asumió Agustín de Eyzaguirre, quien tampoco se mostró capaz de controlar las facciones políticas y de responder a las demandas surgidas al interior del mismo Congreso por una conducción más decidida y fuerte que liderara el gobierno. Como consecuencia de la situación política desmedrada del país, el coronel Enrique Campino aprovechó la crisis orquestando un golpe de Estado, el 24 de enero de 1827, con el fin de deponer a Eyzaguirre y ascender él al poder en calidad de vicepresidente. Sin embargo, el plan fue frustrado, y derrotado el movimiento. Al día siguiente del conato, asumía la presidencia Ramón Freire, siendo electo por el Congreso Nacional. Este fue el principio del fin para la experiencia federal en Chile.

que se publicó en la Abeja chilena sobre sistemas federativos en general y con relación a Chile, Santiago, Imprenta de la Independencia, 1825. Rocafuerte contestó a Egaña con un opúsculo publicado en Londres. Véase Rocafuerte, Vicente, Cartas de un americano: sobre las ventajas de los gobiernos republicanos federativos, Londres, Imprenta española de M. Calero, 1826.

83. Almeyda, Aniceto, Cartas de don Mariano Egaña a su padre 1824-1829, Santiago, Sociedad de Bibliófilos Chilenos, 1948. Carta fechada el 20/11/1826.

84. SCL, vol. XII, p. 104. 
Freire demostró poco interés en continuar con el proceso de organización federal, moviendo prontamente sus influencias al interior del Congreso y entre las asambleas provinciales del país para conseguir el abandono de dicha política. Carente del apoyo necesario para subsistir, tan repentinamente como el entusiasmo inicial en su instauración, el experimento federal en Chile no pudo prevalecer. Así lo demostró el cierre de las sesiones del Congreso a fines de 1827, sin adoptar medida alguna sobre el proyecto de constitución federal ni tampoco sobre la continuación del sistema, y la derogación de las leyes que habilitaban su funcionamiento, a principios de 1828 , siendo artífice de este plan la nueva administración encabezada desde mayo de 1827 por Francisco Antonio Pinto.

No obstante, podría pensarse fácilmente que las asambleas provinciales, como instituciones de gobierno local, podrían haber sufrido algún perjuicio producto de los vaivenes de la política nacional, pero en realidad, el sistema de asambleas no solo sobrevivió al fallido intento de aplicar un régimen federal en Chile, sino que incluso salió fortalecido. Sumándose a Santiago, Concepción y Coquimbo, ahora cinco nuevas asambleas se erigían como espacios de representación local en sus respectivas provincias ${ }^{85}$ reconociendo y precaviendo el gobierno central de mantener su existencia y no menoscabar su autoridad, salvaguardando sus atribuciones por medio de un reglamento provisional hasta que se promulgara una nueva constitución que estableciese el tipo de Estado que se quería para Chile.$^{86}$ Para este fin, se consultó a las asambleas —y por medio de ellas a las respectivas municipalidades- su preferencia, contestando solamente cuatro de las ocho provincias (Santiago, Concepción, Valdivia y Coquimbo). ${ }^{87}$ La capital se opuso a cualquier régimen que insinuase federación, Concepción dio una respuesta ambigua solo inclinándose por el sistema «popular representativo», mientras que Valdivia y Coquimbo se pronunciaron a favor del régimen federal. Frente a esta falta de decisión, Pinto decidió obrar bajo hechos consumados. Convocó a un nuevo Congreso Nacional, que se reunió con el carácter de constituyente, y que inició rápidamente sus trabajos para la redacción de una nueva carta política, ${ }^{88}$ prescindiendo de una nueva consulta a las provincias. ${ }^{89} \mathrm{La}$ nueva Carta Fundamental fue promulgada con pompa y circunstancia el 8 de agosto de 1828.

85. Las provincias creadas fueron, de norte a sur: Aconcagua, Colchagua, Maule, Valdivia, Chiloé. Sanhueza, María Carolina, «La primera división...», cit., p. 487.

86. Briceño, Ramón, Memoria histórico-crítica..., cit., p. 460. Dicho reglamento fue redactado por Infante, aunque morigerado en gran parte por el Congreso.

87. Boletín de leyes y decretos del gobierno de Chile, n. ${ }^{\circ}$, libro III, Ley de 22 de junio de 1827, artículo $1 . \circ$.

88. Pérez, Rodrigo, «Los inicios de la enseñanza del Derecho Constitucional en el Chile decimonónico: el Liceo de Chile y el Colegio de Santiago (1828-1831)», Anuario de Estudios Americanos, vol. 68, n. ${ }^{\circ}$ 1, Sevilla, 2011, p. 144; Ocaranza, Francisco, «La Constitución Política de 1828, testimonio del ideario liberal», Ars Boni et Aequi, n. ${ }^{\circ}$ 4, Santiago, 2008, p. 39; Ossa, Juan Luís, «La actividad política...», cit., p. 92, 120-121.

89. Bravo Lira, Bernardino, «El primer constitucionalismo en Chile (1811- 1861)», Revista de Estudios Histórico-Jurídicos, n. ${ }^{\circ}$ XV, Valparaíso, 1992-1993, p. 318; Donoso, Ricardo, Las ideas políticas..., cit., p. 82. 


\section{Unión sin centralización}

En el preámbulo de la Constitución de 1828, el presidente Francisco Antonio Pinto, refiriéndose al sistema de gobierno local instaurado por el nuevo Código Político, señalaba:

Las provincias no fluctuarán en lo sucesivo entre turbulencias peligrosas y una dependencia ilimitada del Gobierno. La Constitución ha modelado su mecanismo, conforme lo aconsejaban las lecciones de la experiencia, y las circunstancias peculiares al país. Ellas no harán el sacrificio de su individualidad, ni se verán segregadas del cuerpo respetable a que pertenecen. La prudente determinación de sus facultades y atribuciones impondrá perpetuo silencio a quejas infundadas, y a reclamaciones imprudentes; y seguras del bien que pueden hacer, sin exceder aquellos límites, la ventura que ellas mismas se fabricarán, formará la ventura de la Nación entera, y contribuirá esencialmente a su reposo y a su armonía.

La promesa de un equilibrio entre las potestades del gobierno central y la mantención de un espacio de representación y decisión a nivel local, sumado a la existencia de un Poder Ejecutivo moderado por la influencia del Congreso y de las mismas asambleas, ${ }^{90}$ parecía haberse convertido en uno de los alicientes que llevaron a un rápido consenso sobre el marco institucional que creaba la nueva carta fundamental. La pervivencia de cierto ámbito de representación y autonomía provincial pareciera ser en parte una transacción con los federalistas, así como también una forma de mantener a raya cualquier resurgimiento de suspicacias frente a un posible reflujo centralizador por parte de Santiago. José Joaquín de Mora, a quien se le ha adjudicado erróneamente la redacción de la Constitución, siendo solo uno de sus revisores, se mostró particularmente reacio a entregar a las provincias algún grado de autonomía y sin embargo, pese a sus esfuerzos, pervivieron en el proyecto y posteriormente en la Constitución. ${ }^{91}$ De esta forma, quedaba consagrado constitucionalmente el compromiso que aseguraba a las provincias un espacio de intervención en las decisiones políticas que fueran atingentes a sus propios intereses y gobierno.

90. Constitución Política de la República de Chile, 1828, artículos 46-48, 81-85 y 114-115. Véase también los versos publicados dedicados a la Constitución en La Clave, n. ${ }^{\circ} 84,17 / 02 / 1829$. Un juicio similar realiza Briceño, Ramón, Memoria bistórico-crítica..., cit., p. 219. Aunque crítico del sistema creado por la constitución, Jaime Eyzaguirre llega a una conclusión similar. Ver. Eyzaguirre, Jaime, Historia de las instituciones políticas y sociales de Chile, Santiago, Universitaria, 1981, p. 77.

91. Rodríguez, Gregorio F., «Epistolario: cartas de don José Joaquín de Mora a don Florencio Varela», Revista Chilena de Historia y Geografía, n. ${ }^{\circ}$ 54, Santiago, 1920. Mora le señalaba a Varela en carta del 8/03/1828: «Aseguro a V. que veo con dolor que la Argentina tiene mucho partido, porque tiene grandísimos defectos, sobre todo con respecto a este país, donde arraigado de un modo firmísimo el régimen municipal, las asambleas provinciales sólo podrían ocasionar entorpecimiento y anarquía». Posteriormente en carta del 11/05/1828 sentenciaba resignado: «El proyecto está redactado. Un amigo de V. hizo hasta la mitad, pero al acercarse a la piedra de toque, a las atribuciones de las provincias, presentó a la comisión una memoria manifestando sus opiniones, directamente opuestas a las de la mayoría (...) la nueva Constitución irá a parar a la nulidad de letra muerta, comme tant d'autres». 
En el caso particular de las asambleas provinciales reguladas por las Constitución de 1828, estas poseían una amplia gama de atribuciones, listadas en su artículo 114, que incluían nombrar senadores, proponer en terna los nombramientos de intendentes y viceintendentes al Ejecutivo, autorizar los presupuestos municipales, examinar cuentas y corregir sus abusos y formar el censo estadístico de su provincia respectiva. Si bien eran muchos menos los ámbitos de gobierno y control en comparación a los reglamentos de 1825 y 1827 , las asambleas continuaban poseyendo una cantidad de influencia y poder respetable. Ramón Briceño se refería a este punto con una analogía en la que indicaba que:

(...) la asamblea viene a ser con respecto al cabildo, poco más o menos, lo mismo que el intendente con respecto al gobernador local, y que idéntica relación hay entre asamblea y congreso, que entre el intendente de la provincia y el presidente de la República: esta es una jerarquía que no se interrumpe. ${ }^{92}$

Bajo este nuevo marco, el trabajo de las asambleas, pese a la disparidad de recursos entre las provincias, se dio en forma relativamente estable y el cumplimiento de sus funciones se adecuó conforme a los presupuestos constitucionales. ${ }^{93}$ Sin ser un cuerpo legislativo, ya que le estaba vedado el ejercicio de dicha potestad, la asamblea se convirtió en el órgano ejecutivo-administrativo de la provincia, desarrollándose como un contrapeso relativo frente a la autoridad del presidente de la República, limitando su injerencia en el nombramiento de las autoridades provinciales, tanto por medio del ejercicio de su facultad de proposición de cargos, así como a través del uso de su función recaudadora e impositiva. Asimismo, su facultad controladora le permitió supervigilar a los cabildos — representados a su vez en la asamblea- en materia presupuestaria y de elecciones, lo que provocó un fenómeno importante: el rol de representación se invirtió. Durante buena parte de la década de 1820, los cabildos resultaron ser el estadio primario de representación política, al punto que eran estas instituciones las que convocaban las asambleas y sus representantes las constituían. Ahora, bajo el imperio de la nueva Constitución, las asambleas, reconocidas constitucionalmente, fueron colocadas en un nivel superior frente a sus respectivos cabildos, ejerciendo sobre ellos una serie de controles, resultando en una transferencia de poder e influencia hacia las asambleas. Este sistema, en definitiva, acomodó las demandas por autonomía y la defensa de los intereses locales, con un modelo de Estado

92. Briceño, Ramón, Memoria bistórico-crítica..., cit., p. 220. Este autor concluía que una de las ventajas de las asambleas era «servir para hacer efectiva la Constitución en los pueblos, y poner atajo a las arbitrariedades de los intendentes». De este modo servía también como un mecanismo de peso y contrapeso efectivo y material.

93. Esto puede verse en las actas de las asambleas provinciales. Para Coquimbo, AN-FCM, vol. 2, Actas de la Asamblea Provincial de Coquimbo, 1825-1829; para Santiago, AN-FV, vol. 258, Actas de la Asamblea Provincial de Santiago, 1829-1830. Lamentablemente, para el período en comento, el resto de las actas de otras asambleas se encuentran perdidas. Para poder estudiar su funcionamiento ha sido necesario reconstruirlas por medio del estudio de copias de sus actas u oficios enviados a otras asambleas o al gobierno central. 
unificado a la vez que descentralizado, sin necesidad de crear un régimen federal que la mayor parte de las provincias no habían pedido ni estaban en condiciones de desarrollar ni financiar. ${ }^{94}$

No obstante, pese la relación auspiciosa que parecía inaugurada entre el gobierno central y las provincias de Chile por medio de la Carta de 1828, la realidad era que, superado el conflicto, la lucha se trasladó al campo de la disputa por el poder máximo en la República entre las distintas facciones políticas de la época. Los pelucones, en tándem con los o'higginistas, y los estanqueros, ${ }^{95}$ denunciaban la incapacidad del gobierno de Pinto para resolver los problemas crónicos que aquejaban a la República: conservar el orden, revitalizar la economía y solventar los pagos de la deuda externa. Por su parte, los pipiolos, que habían subido al poder junto con Pinto, temían perderlo por vía eleccionaria, por lo que recurrieron a los mecanismos clásicos de la intervención electoral, que en el futuro plagarían el sistema de elecciones en Chile. ${ }^{96}$ Los conflictos entre estos grupos terminaron por marcar finalmente el destino y conformación del Estado en Chile.

El 4 de octubre de 1829, la Asamblea Provincial de Concepción, denunciando el fraude cometido por la mayoría parlamentaria en el Congreso Nacional con motivo de la elección vicepresidencial ocurrida ese mismo año, ${ }^{97}$ desconoció por irregular la elección del presidente y vicepresidente, pero también se erigió en una condena contra el régimen de gobierno pipiolo, denunciando «la multitud de actos de absolutismo (...) [tanto] en

94. Ricardo Donoso también sentencia (de la misma forma que lo hace Mora en sus cartas a Varela citadas más arriba), que la autonomía concedida a las provincias no era oportuna, dado el estado de agitación en que se hallaban, sin dar mayores evidencias al respecto. cf. Donoso, Ricardo, Las ideas políticas en Chile, México D.F., Fondo Cultura Económica, 1946, p. 84. Una tesis similar la desarrolla el mismo autor en una obra anterior y menos conocida. Véase Donoso, Ricardo, Desarrollo político y social de Chile desde la Constitución de 1833, Santiago, Universitaria, 1942.

95. Los pelucones tradicionalmente han sido considerados representantes de los sectores terratenientes más tradicionales, ligados en parte con las familias más prestigiosas de ciudades como Concepción y Santiago, a la vez que con el clero. Los o'higginistas, era los partidarios del desterrado ex Director Supremo y abogaban por la creación de un gobierno fuerte y autoritario, a más del regreso de su héroe. Por otro lado, de los estanqueros, al igual que los o'higginistas, defendían la creación de un Poder Ejecutivo fuerte, aunque externamente rechazaban el personalismo caudillesco, defendiendo un régimen centralizador e impersonal. Ver. Collier, Simon, Ideas and politics..., cit., p. 324; Eyzaguirre, Jaime, Historia de las instituciones..., cit., p. 77 y Vargas, Juan Eduardo, «El pensamiento político del grupo estanquero (1826-1829)», Historia, n. ${ }^{\circ}$ 9, Santiago, 1970, pp. 7-35.

96. Eyzaguirre, Jaime, Historia de las instituciones..., cit., p. 77; Bravo Lira, Bernardino, Por la razón..., cit., p. 288; Galdames, Luis, Historia de Chile: La evolución constitucional 1810-1925, Santiago, Imprenta Balcells, 1926, pp. 788-789. En contra de esta tesis se puede ver Errázuriz, Federico, Chile bajo el imperio de la Constitución de 1828, Santiago, Imprenta Chilena, 1861, p. 63 y ss. Barros Arana se hace cargo de las alegaciones contra las acciones de los «pipiolos», pero no emite juicios al respecto. Ver Barros Arana, Diego, Historia general..., cit., tomo XV, pp. 247 y ss.

97. Esto tiene relación con el artículo 72 de la Constitución de 1828. Las dos mayorías relativas recayeron en Francisco Ruiz-Tagle (pelucón) y Joaquín Prieto (o’higginista). Tomando en cuenta que Francisco Antonio Pinto se negó a asumir como presidente, la elección vicepresidencial se convirtió en la verdadera carrera por el poder, pero también su resultado significó la perdida del mismo por parte de los pipiolos. Esto los llevó a torcer el texto del artículo 72, forzando la elección de la tercera mayoría relativa, que recayó sobre el intendente Joaquín Vicuña. 
las cámaras como en el Ejecutivo». ${ }^{98}$ Concepción retiró los poderes a los diputados que la representaban y conminó a otras provincias a hacer lo mismo. La provincia del Maule siguió su ejemplo, y entre ambas montaron un ejército para derrocar a un gobierno que consideraban ilegítimo, repitiéndose en parte las circunstancias del período 1822-1823 y lo acontecido en 1825. Este fue el inicio de la guerra civil de 1829-1830.

Dos batallas sellaron el destino del predominio pipiolo. Ochagavía, en diciembre de 1829, y Lircay, en abril de 1830. Pero más importante que esto fue el nuevo orden de cosas que surgió de las cenizas de la guerra. Derrotados los pipiolos, sus enemigos se hicieron con el poder. Quien ha sido sindicado por buena parte de la historiografía como el arquitecto del régimen, Diego Portales, fue ministro universal de las breves administraciones peluconas entre 1830 y 1831, bastándole ese año para reprimir cualquier atisbo de oposición al nuevo régimen. ${ }^{99}$ Pero Portales lejos de ser —o querer ser- un líder, dejó espacio para que otros se encargasen de construir un nuevo orden de cosas para Chile. Andrés Bello, Juan y Mariano Egaña, Manuel José Gandarillas, Gabriel Tocornal, Manuel Rengifo, Diego José Benavente, ${ }^{100}$ entre otros, fueron los estadistas que ayudaron a construir un régimen centralizador y autoritario, en el que las asambleas provinciales parecían contrariar precisamente los presupuestos en los que se fundaba el nuevo régimen, y por lo tanto fueron abolidas al promulgarse la nueva constitución en $1833 .{ }^{101}$

La supresión de las asambleas sobrevino bajo los auspicios del régimen pelucón, sorprendentemente sin ninguna reacción negativa por parte de las provincias. Sin entrar a desarrollar dicha arista con mayor latitud, es dable especular que los motivos de dicha inacción pueden deberse al cansancio frente a la constante experimentación y desorden aparejado. No obstante, más plausible pareciera ser que un proceso de cooptación paulatina de las élites locales se había puesto en marcha por parte de las autoridades de Santiago, adscribiendo a los individuos más relevantes de las provincias a las políticas del gobierno central. ${ }^{102}$ Asimismo, los dos primeros presidentes de la República del régimen

98. AN-FV, vol. 815, Acta de la Asamblea Provincial de Concepción, 4/10/1829.

99. Portales volvería a ser ministro entre 1835 y 1837 , cuando la arquitectura constitucional ya se encontraba consolidada. En todo caso, la cantidad de estudios y trabajos que existen sobre Diego Portales y su hercúlea influencia en la construcción del estado chileno es enorme, aunque buena parte de ella no da argumentos sustanciales para apoyar dicha hipótesis. En los últimos treinta años se han publicado estudios que contradicen la noción generalizada sobre Portales. A modo de ejemplo véase Villalobos, Sergio, Portales, una falsificación bistórica, Santiago, Editorial Universitaria, 1989.

100. Jaksic, Iván, Andrés Bello: la pasión por el orden, Santiago, Universitaria, 2000; Brahm, Enrique, Mariano Egaña: derecho y política en la fundación de la República, Conservadora, Santiago, Centro de Estudios Bicentenario, 2007; Collier, Simon, Ideas and politics..., cit., pp. 260-286, en lo relativo a Juan Egaña. Esto puede complementarse con Infante, Javier, «Mercantilismo, proteccionismo y orden público económico en el pensamiento constitucional de Juan Egaña», Revista de Estudios Histórico-Jurídicos, n. ${ }^{\circ}$ 35, Valparaíso, 2013, pp. 547-566 y Pérez Godoy, Fernando, «Johannes Heineccius y la historia trasatlántica del Ius Gentium», Revista Chilena de Derecho, vol. 44, n. ${ }^{\circ} 2$, Santiago, 2017, pp. 539 y ss.

101. Letelier, Valentín, La gran convención de 1831-1833: recopilación de las actas, sesiones, discursos, proyectos y artículos de diarios a la Constitución de 1833, Santiago, Imprenta Cervantes, 1901, pp. 315 y 317.

102. Brahm, Enrique, Mariano Egaña..., cit., pp. 56-58. Otro argumento a favor de ello fue que, durante los 25 años siguientes, el gobierno central dio pasos relativamente tímidos para conseguir un mayor control a 
pelucón provinieron de familias influyentes de Concepción: Joaquín Prieto (1831-1841), fue quien dirigió las tropas revolucionarias contra Santiago en 1829, y su sobrino Manuel Bulnes (1841-1851), fue su lugarteniente durante la guerra civil. Por cierto, estos nombres fueron un reaseguro de que estos hombres tenían sus raíces y redes no en Santiago, sino en provincia.

El gobierno en Santiago se convirtió eventualmente en proveedor de cargos, en dador de prebendas y en motor del desarrollo público en Chile desde el segundo tercio del siglo XIX, de la mano de las administraciones peluconas de Prieto, Bulnes y Montt (18311861) y luego con la pentarquía liberal de Pérez, Errázuriz, Aníbal Pinto, Santa María y Balmaceda (1861-1891). Sin embargo, pese a la aparente victoria del centralismo y del «Estado en forma», parafraseando a Alberto Edwards, a lo largo de la segunda mitad del siglo XIX, en dos ocasiones las provincias volvieron a levantarse, enarbolando la bandera de los derechos locales contra la autoridad de la capital. Primero en 1851, denunciando la ilegitimidad de la elección de Manuel Montt, Concepción y Coquimbo hicieron lo propio, declarando la primera su independencia, bajo los mismos términos que lo hiciera en 1822. Por otra parte, entre 1858 y 1859, en la zona de Coquimbo y Atacama, se verificó una revolución que se alzó frente a la intervención del Estado central en las municipalidades y las juntas de minería de la zona. En ambos casos la bandera de lucha fue la autonomía provincial y la protección de los derechos de la provincia frente a la intervención estatal, aunque también en los dos ejemplos, las revueltas fueron un fracaso rotundo desde el punto de vista militar, prevaleciendo la voluntad de la capital por sobre la de las provincias. ${ }^{103}$

\section{Conclusiones}

En el desarrollo de este trabajo, se ha querido estudiar el surgimiento y desarrollo de las asambleas provinciales en Chile, durante el período post-independentista, entendiendo a estas instituciones como un actor relevante en la construcción del Estado chileno, así como también la expresión de un contrapeso político e institucional de parte de las élites locales a la preeminencia de Santiago respecto al resto de las provincias del país. En este sentido, la institucionalización paulatina de las asambleas, especialmente desde 1825 en adelante, demuestran su importancia como un vehículo para la representación de las demandas provenientes del nivel local e incluso como un polo de resistencia ante los intentos de avance centralizador de la capital.

nivel local. El primer proyecto de ley de Régimen Interior fue formulado en 1836, pero sin transformarse en ley, debiendo esperar a 1844 para que se promulgara una ley definitiva sobre la materia. Ver SCL, vol. XXIV, Doc. 366. La ley definitiva fue promulgada el 10 de enero de 1844.

103. Fundamental a esta situación fue la promulgación de la ley de municipalidades de 1854, que ponía bajo control directo del gobierno central a los municipios. Valdebenito, Alfonso, Evolución jurídica del régimen municipal en Chile (1541-1971), Santiago, Editorial jurídica de Chile, 1973, p. 33. 
Por otra parte, también ha sido objeto de este trabajo el poner de relieve que los conflictos que dieron origen a las asambleas fueron indicadores de la transición paulatina que se verificó en el paso del Antiguo Régimen colonial al modelo revolucionario, siendo las asambleas provinciales un estadio superior de la representación corporativa del Antiguo Régimen, que tradicionalmente había estado circunscrita a los cabildos. Comprueba que los movimientos asambleístas de 1822-1823 y de 1825 estuvieron marcados por la presencia constante del poder municipal en su gestación, y que la invocación de los «derechos de los pueblos» y la persistencia de conceptos como la retroversión de la soberanía, fueron elementos propios de la cultura jurídica y política durante la época colonial que coexistieron junto con el discurso revolucionario.

Una forma en que se expresó quizás más claramente esta tensión fue entre 1825 y 1828, período en el cual Chile adoptó el sistema federal como base de su organización política. Como fue dicho más arriba, el sistema federal pareció salvaguardar los derechos intrínsecos de las provincias, asegurándoles un espacio de autonomía administrativa considerable, si se toma en cuenta la legislación promulgada, el reconocimiento legal de las asambleas y el proyecto de constitución federal, que finalmente fue desechado. Por otro lado, el régimen federal pareció satisfacer los escrúpulos de los revolucionarios más radicales, que veían en su adopción una forma de terminar con los disensos entre las provincias bajo principios republicanos y constitucionales conciliando la pugna entre centro y provincia, entre la soberanía nacional y las soberanías locales y particulares. Su fracaso, en parte por la disparidad de recursos entre las provincias más pequeñas, la falta de un compromiso político firme de las autoridades centrales para con el sistema, la continuidad de la crisis económica y el descontento en el ejército, fueron factores que terminaron por hacer naufragar el modelo federal, llevaron a que fuera sustituido por un sistema unitario, pero descentralizado, en el que las asambleas provinciales tuvieron un lugar destacado en el modelo constitucional. Estas fueron reconocidas en el texto de la Constitución, asumiendo un rol coadyuvante al intendente y ocupando una función propiamente ejecutiva. De esta forma, sin dividir la soberanía entre nacional y local, las asambleas podían participar directamente del gobierno de su provincia, pero al mismo tiempo, se reconcilió con la protección corporativa de sus intereses y prebendas dentro del sistema republicano adoptado por Chile, hasta su abolición en 1833, bajo el auspicio de una nueva constitución, pero al mismo tiempo, de un nuevo pacto al interior de la élite, en el que el presidente de la República, como cabeza de la administración, pasó a convertirse en un árbitro de la vida pública, en gendarme necesario cuando las circunstancias lo requerían, pero también en un distribuidor de cargos y poder para la élite.

\section{Bibliografía}

Alemparte, Julio, El cabildo en Chile colonial, Santiago, Editorial Andrés Bello, 1966.

Almeyda, Aniceto, Cartas de don Mariano Egaña a su padre 1824-1829, Santiago, Sociedad de Bibliófilos Chilenos, 1948. 
Amunátegui, Domingo, «Génesis de la independencia de Chile», Anales de la Universidad de Chile, n. ${ }^{\circ} 118$, Santiago, 1960, pp. 146-164.

Amunátegui, Miguel Luis, La dictadura de O’Higgins, Santiago, Imprenta de J. Belín, 1855.

—, Los precursores de la independencia de Chile, tomo I, Santiago, Imprenta de la República, 1870.

Barbier, Jacques, «The Culmination of the Bourbon Reforms, 1787-1792», Hispanic American Historical Review, vol. 57, n. ${ }^{\circ}$ 1, Washington, 1977, pp. 51-68.

Barrientos, Javier, La cultura jurídica en el Reino de Chile: bibliotecas de ministros de la Real Audiencia de Santiago (siglos XVII-XVIII), Santiago, Ediciones Universidad Diego Portales, 1992.

Barros Arana, Diego, Historia general de Chile, tomo XIII Santiago, CIDBA-Universitaria, 16 tomos, 2000.

Brahm, Enrique, Mariano Egaña: derecho y política en la fundación de la República, Conservadora, Santiago, Centro de Estudios Bicentenario, 2007.

Bravo Lira, Bernardino, La universidad en la historia de Chile, 1622-1992, Santiago, Pehuén, 1992.

—, «El primer constitucionalismo en Chile (1811- 1861)», Revista de Estudios Histórico-Jurídicos, n. ${ }^{\circ}$ XV, Valparaíso, 1992-1993, pp. 303-331.

-, Por la razón o la fuerza: el estado de derecho en la bistoria de Chile, Santiago, Ediciones Universidad Católica de Chile, 1996.

-, Constitución y reconstitución: historia del Estado en Iberoamérica (siglos XVI al XXI), Santiago Abeledo Perrot, Legal Publishing, 2010.

Briceño, Ramón, Memoria histórico-critica del derecho público chileno, Santiago, Imprenta de Julio Belín, 1849.

Burlando, Giannina, «Virtud política y método histórico rupturista en Francisco Suárez», Veritas, n. ${ }^{\circ}$ 32, Casablanca, 2015, pp. 59-78.

Bushnell, David, «La independencia de América del Sur española», en Bethell, Leslie, Historia de América Latina, tomo V, Barcelona, Crítica, 1991, pp. 75-123.

Campos Harriet, Fernando, Veleros franceses en el Mar del Sur, Santiago, Zig-Zag, 1964.

Carrasco, Sergio, Génesis y vigencia de los textos constitucionales chilenos, Santiago, Editorial Jurídica de Chile, 2002.

Castillo, Vasco, La creación de la República. La filosofía pública en Chile 1810-1830, Santiago, LOM, 2009.

Cavieres, Eduardo, Sobre la independencia en Chile. El fin del Antiguo Régimen y los orígenes de la representación moderna, Valparaíso, Ediciones Universitarias de Valparaíso, Pontificia Universidad Católica de Valparaíso, 2012.

Chiaramonte, José Carlos, Nación y Estado en Iberoamérica. El lenguaje político en tiempo de las independencias, Buenos Aires, Sudamericana, 2004.

-, Fundamentos políticos e intelectuales de las independencias. Notas para una nueva historia intelectual de Iberoamérica, Buenos Aires, Teseo, 2010.

Collier, Simon, Ideas and Politics of Chilean Independence, 1808-1833, Cambridge, Cambridge University Press, 1967.

Dauxion Lavaysse, Jean Joseph (Amerícola), Del Federalismo y la Anarquía, Santiago, Imprenta Nacional, 1823.

Dawyd, Darío, «Las independencias hispanoamericanas y la tesis de la influencia de las doctrinas populistas», Temas de Historia argentina y americana, n. ${ }^{\circ}$ 16, Buenos Aires, 2010, pp. 99-128.

Del Alcázar, Joan, et al., Historia contemporánea de América, Valencia, Universidad de Valencia, 2007. 
Del Valle, Laura Cristina, Los hijos del poder. De la élite capitular a la Revolución de mayo: Buenos Aires 1776-1810, Buenos Aires, Prometeo Libros, 2014.

Donoso, Ricardo, Desarrollo politico y social de Chile desde la Constitución de 1833, Santiago, Universitaria, 1942.

—, Las ideas políticas en Chile, México D.F., Fondo Cultura Económica, 1946.

Dym, Jordana, From Sovereign Villages to National States. City, State and Federation in Central America 1759-1839, Albuquerque, University of New Mexico Press, 2006.

—, «Our Pueblos, Fractions with No Central Unity: Municipal Sovereignty in Central America, 1808-1821», Hispanic American Historical Review, vol. 86, n. ${ }^{\circ}$ 3, Washington, 2006, pp. 431-466.

Edwards, Alberto, La fronda aristocrática, Santiago, Editorial del Pacífico, 1972.

Errázuriz, Federico, Chile bajo el imperio de la Constitución de 1828, Santiago, Imprenta Chilena, 1861.

Errázuriz, Isidoro, Historia de la administración Errázuriz, Santiago, Imprenta General de Prisiones, 1935.

Etchepare, Jaime, «El federalismo, antecedentes, características y su fugaz vigencia en Chile 18231830», Revista Libertador O'Higgins, Santiago, Instituto O'Higginiano, n. ${ }^{\circ} 13,1996$, pp. 65-73.

Eyzaguirre, Jaime, Historia de las instituciones politicas y sociales de Chile, Santiago, Universitaria, 1981.

—, Ideario y ruta de la emancipación chilena, Santiago, Universitaria, 1986.

Fernández, Joaquín, «De la colaboración con el Estado a la protesta regionalista: la Junta de Minería de Copiapó desde las Reformas Borbónicas hasta la Guerra Civil de 1859», Revista de Historia y Geografía, Universidad Católica Silva Henríquez, n. ${ }^{\circ} 31$, Santiago, 2014, pp. 19-46.

Font, Pablo, «El núcleo de la doctrina de Francisco Suárez sobre la resistencia y el tiranicidio», Pensamiento, vol. 69, n. ${ }^{\circ}$ 260, Madrid, 2013, pp. 493-521.

Galdames, Luis, Historia de Chile: La evolución constitucional 1810-1925, Santiago, Imprenta Balcells, 1926.

García-Gallo, Alfonso, «El derecho indiano y la independencia de América», Revista de Estudios Políticos, n. ${ }^{\circ}$ 60, vol. XL, Madrid, 1951, pp. 157-180.

García-Huidobro Becerra, Cristóbal, «El reglamento constitucional provisorio de 1812: reflexiones para un bicentenario», Revista Chilena de Derecho, vol. 39, n. ${ }^{\circ}$ 1, Santiago, 2012, pp. 235-243.

Gazmuri, Cristián «Libros e ideas políticas francesas en la gestación de la independencia de Chile», Caravelle. Cabiers du monde bispanique et luso-brésilien, n. ${ }^{\circ}$ 54, París, 1990, pp. 179-207.

Goldman, Noemí (ed.), Lenguaje y revolución: conceptos políticos clave en el Río de la Plata, 17801850, Buenos Aires, Prometeo, 2010.

Góngora, Mario, «Aspectos de la Ilustración Católica en el pensamiento y la vida eclesiástica chilena (1770-1814)», Historia, n. ${ }^{\circ} 8,1969$, pp. 43-73.

—, Estudios de historia de las ideas y de historia social, Valparaíso, Ediciones Universitarias de Valparaíso, 1980, pp. 71-125.

González Echenique, Javier, «Un estudio de influencias doctrinarias en la Independencia: El concepto de diputado o representante popular. 1810-1828», Historia, n. ${ }^{\circ}$ 6, Santiago, 1967, pp. 127-152.

Guerra, François Xavier, Modernidad e independencias: ensayos sobre las revoluciones hispánicas, México D.F., Fondo de Cultura Económica, 1993.

Hanisch, Walter, En torno a la filosofía en Chile: (1594-1810), Santiago, Universidad Católica de Chile, 1963. 
Heise, Julio, Años de formación y aprendizaje políticos 1810-1833, Santiago, Universitaria, 1978.

Herzog, Tamar, Defining nations. Immigrants and citizens in Early Modern Spain and Spanish America, New Haven, Yale University Press, 2003.

Hoberman, Louisa y Susan Socolow (comp.), Ciudades y sociedad en Latinoamérica colonial, México D.F., Fondo de Cultura Económica, 1992.

Huneeus Pérez, Andrés, Historia de las polémicas de Indias en Chile durante el siglo XVI, 1536-1598, Santiago, Editorial Jurídica de Chile, 1960.

Infante, Javier «Mercantilismo, proteccionismo y orden público económico en el pensamiento constitucional de Juan Egaña», Revista de Estudios Histórico-Jurídicos, n. ${ }^{\circ}$ 35, Valparaíso, 2013 , pp. 547-566.

-, Autonomía, Independencia y República en Chile, 1810-1828, Santiago, Centro de Estudios Bicentenario, 2014.

Jaksic, Iván, Andrés Bello: la pasión por el orden, Santiago, Universitaria, 2000.

Jocelyn-Holt, Alfredo, La independencia de Chile: Tradición modernización y mito, Santiago, DeBolsillo, 2009.

Kaplan, Lawrence, Entangling Alliances with None: American Foreign Policy in the Age of Jefferson, Kent, Kent University Press, 1987.

Kinsbruner, Jay, The Colonial Spanish-American City: Urban Life in the Age of Atlantic Capitalism, Austin, University of Texas Press, 2005.

Letelier, Valentín, La gran convención de 1831-1833: recopilación de las actas, sesiones, discursos, proyectos y artículos de diarios a la Constitución de 1833, Santiago, Imprenta Cervantes, 1901.

Levene, Ricardo, El mundo de las ideas y la revolución hispanoamericana de 1810, Santiago, Editorial Jurídica de Chile, 1956.

Lockhart, James y Stuart Schwartz, Early Latin America. A bistory of colonial Spanish America and Brazil, Cambridge, Cambridge University Press, 1983.

López, Elvira, El proceso de construcción estatal en Chile. Hacienda pública y burocracia (18171860), Santiago, DIBAM-CIDBA, 2014.

Lorenzo, Santiago y Rodolfo Urbina, Origen de las ciudades chilenas, Santiago, Andrés Bello, 1983.

—, «Concepto y funciones de las villas chilenas del siglo XVIII», Historia, n. ${ }^{\circ}$ 22, Santiago, 1987, pp. 91-105.

Luque Talaván, Miguel, Un universo de opiniones: la literatura jurídica indiana, Madrid, CSIC, 2003.

Mellafe, Rolando et al., Historia de la Universidad de Chile, Santiago, Editorial de la Universidad de Chile, 1992.

Meza, Néstor, La conciencia política chilena durante la monarquía, Santiago, Universitaria, 1958.

Ocampo, Javier, «Independencia y Estado Nación», en Ocampo, José Fernando, Historia de las ideas políticas en Colombia, Bogotá, Taurus, 2008, pp. 23-66.

Ocaranza, Francisco, «La Constitución Política de 1828, testimonio del ideario liberal», Ars Boni et Aequi, n. ${ }^{\circ}$ 4, Santiago, 2008, pp. 31-58.

O'Higgins, Bernardo, Manifiesto que hace a las naciones el Director Supremo de Chile de los motivos que justifican su revolución y la declaración de su independencia, Santiago, Xara y Molinare, 1818.

Ossa, Juan Luis, «La actividad política de Francisco Antonio Pinto: 1823-1828. Notas para una revisión biográfica», Historia, n. ${ }^{\circ}$ 40, vol. 1, Santiago, 2007, pp. 91-128.

Pérez, Joseph y Armando Alberola (eds.), España y América entre la Ilustración y el liberalismo, Alicante-Madrid, Casa de Velásquez, 1993. 
Pérez, Rodrigo, «Los inicios de la enseñanza del Derecho Constitucional en el Chile decimonónico: el Liceo de Chile y el Colegio de Santiago (1828-1831)», Anuario de Estudios Americanos, vol. 68, n. ${ }^{\circ}$ 1, Sevilla, 2011, pp. 141-162.

Pérez Godoy, Fernando, «La presencia de las ideas políticas de Samuel Pufendorf durante la independencia de Chile», Revista de Derecho y Humanidades, n. ${ }^{\circ}$ 17, Santiago, 2011, pp. 1-17.

Pérez Godoy, Fernando, «Johannes Heineccius y la historia trasatlántica del Ius Gentium», Revista Chilena de Derecho, vol. 44, n. ${ }^{\circ}$ 2, Santiago, 2017, pp. 539-562.

Quijada, Mónica, «Las dos tradiciones»: Soberanía popular e imaginarios compartidos en el mundo hispánico en la época de las grandes revoluciones atlánticas», en Jaime Rocafuerte, Vicente, Cartas de un americano: sobre las ventajas de los gobiernos republicanos federativos, Londres, Imprenta española de M. Calero, 1826.

Rodríguez, Gregorio F., «Epistolario: cartas de don José Joaquín de Mora a don Florencio Varela», Revista Chilena de Historia y Geografía, n. ${ }^{\circ}$ 54, Santiago, 1920, pp. 35-66.

Rodríguez, Jaime (coord.), Revolución, independencia y las nuevas naciones de América, Madrid, MAPFRE, 2005, pp. 61-86.

—, «La potestas populi: una revisión del pensamiento político hispánico y la modernidad» en Bragoni, Beatriz y Sara Mata (editoras), Entre la Colonia y la República: insurgencias, rebeliones y cultura política en América del Sur, Buenos Aires, Prometeo, 2008, pp. 29-50.

Rodríguez, Jaime, The Independence of Spanish America, Cambridge, Cambridge University Press, 2009.

Salazar, Gabriel, Construcción de Estado en Chile (1800-1837), Santiago, Sudamericana, 2006.

Sanhueza, María Carolina, «La primera división político-administrativa de Chile, 1811-1826», Historia, vol. 41, n. ${ }^{\circ}$, Santiago, 2008, pp. 447-493.

Valdebenito, Alfonso, Evolución jurídica del régimen municipal en Chile (1541-1971), Santiago, Editorial jurídica de Chile, 1973.

Valencia Avaria, Luis, Anales de la República de Chile, Santiago, Andrés Bello, 1986.

Valenzuela, Renato, Bernardo O'Higgins. El estado de Chile y el poder naval en la independencia de los países de América del Sur, Santiago, Andrés Bello, 1999.

Vargas, Juan Eduardo, «El pensamiento político del grupo estanquero (1826-1829)», Historia, n. ${ }^{\circ}$ 9, Santiago, 1970, pp. 7-35.

Villamil Concha, Enrique, «Vida de Don Manuel Blanco Encalada», Revista Chilena de Historia y Geografía, Año IX, tomo XXXVI Santiago, 1919, pp. 254-323

Verdo, Geneviève, «¿Soberanía del pueblo o de los pueblos? La doble cara de la soberanía durante la revolución de la independencia (1810-1820)», Andes, Universidad Nacional de Salta, n. ${ }^{\circ} 13$, Salta, 2002.

Vicuña Mackenna, Benjamín, La guerra a muerte, Buenos Aires, Editorial Francisco de Aguirre, 1972.

Villalobos, Sergio, Tradición y reforma en 1810, Santiago, Ediciones de la Universidad de Chile, 1961.

—, Portales, una falsificación histórica, Santiago, Editorial Universitaria, 1989.

Webster, Sir Charles K., Britain and the Independence of Latin America: 1812-1830: select documents from the Foreign Office archives, Londres, Oxford University Press, 1938.

Zañartu, Miguel; Cuadro Histórico del Gobierno del Señor Freire, Lima, s/i, 1826. 